Article

\title{
First Steps at the Cyclotron of Orléans in the Radiochemistry of Radiometals: ${ }^{52} \mathrm{Mn}$ and ${ }^{165} \mathrm{Er}$
}

\author{
Justine Vaudon ${ }^{1}$, Louis Frealle ${ }^{1}$, Geoffrey Audiger ${ }^{1}$, Elodie Dutillly ${ }^{1}$, Mathieu Gervais ${ }^{1}$, \\ Emmanuel Sursin ${ }^{1}$, Charlotte Ruggeri ${ }^{1}$, Florian Duval ${ }^{1,+}$, Marie-Laure Bouchetou ${ }^{1}$, \\ Aude Bombard ${ }^{2}$ and Isidro Da Silva ${ }^{1, *(1)}$ \\ 1 CEMHTI (Conditions Extrêmes et Matériaux: Haute Température et Irradiation), CNRS, UPR3079, \\ University of Orléans, F-45071 Orléans, France; justine.vaudon@insa-rouen.fr (J.V.); \\ louis.frealle@cnrs-orleans.fr (L.F.); geoffrey.audiger@hotmail.fr (G.A.); edutilly@gmail.com (E.D.); \\ mathieu.gervais@insa-rennes.fr (M.G.); sursin.emmanuel@laposte.net (E.S.); \\ ruggeri.charlotte01@gmail.com (C.R.); florian.duval@cnrs-orleans.fr (F.D.); \\ marie-laure.bouchetou@univ-orleans.fr (M.-L.B.) \\ 2 TRISKEM, 3, rue des champs Géons ZAC de l'Eperon 35170 Bruz, France; abombard@triskem.fr \\ * Correspondence: isidro.dasilva@cnrs-orleans.fr; Tel.: +33-238-255-427 \\ † Current address: ISTO, UMR7327, CNRS, University of Orléans, F-45071 Orléans, France.
}

Received: 17 April 2018; Accepted: 10 August 2018; Published: 16 August 2018

\begin{abstract}
This work describes the first real developments in radiochemistry around exotic radionuclides at the cyclotron of Orléans focusing on the radiochemistry of two radiometals ${ }^{165} \mathrm{Er}$ and ${ }^{52} \mathrm{Mn}$. For these developments, targets were irradiated during $0.5-2 \mathrm{~h}$ at a maximum current of $2 \mu \mathrm{A}$. All activities have been determined by radiotracer method. The production of ${ }^{165} \mathrm{Er}$ from a natural Ho target that was irradiated is described. Higher activities of ${ }^{165} \mathrm{Er}$ were obtained via deuteron irradiation then proton with lower ratio ${ }^{165} \mathrm{Er} /{ }^{166} \mathrm{Ho}(400 / 1$ to $8 / 1)$. By using LN2 resin, the separation of adjacent lanthanides was made on various concentrations of $\mathrm{HNO}_{3}(0.3$ to $5 \mathrm{M})$. Weight coefficients $(\mathrm{Dw})$ were defined in a batch test. Then, the first tests of separation on a semi-automated system were made: the ratio ${ }^{166+{ }^{n a t}} \mathrm{Ho} /{ }^{165} \mathrm{Er}$ in an isolated fraction was significantly reduced $(1294 \pm 1183(n=3))$ but the reliability and reproducibility of the system must be improved. Then, a new $\mathrm{Cr}$ powder-based target for ${ }^{52} \mathrm{Mn}$ production was designed. Its physical aspects such as mechanics, thermal resistance and porosity have been studied. Dw for various compositions of eluent Ethanol $/ \mathrm{HCl}$ were evaluated by reducing contact time $(1 \mathrm{~h})$ comparative to the literature. A first evaluation of semi-automated separation $\mathrm{Cr} / \mathrm{Mn}$ has been made.
\end{abstract}

Keywords: ${ }^{165} \mathrm{Er} ;{ }^{52} \mathrm{Mn}$; irradiation; separation; resin; radiometals; heavy Rare Earth Elements (hREE)

\section{Introduction}

The cyclotron of Orléans [1-4] is a research accelerator allowing production of many beam types such as the proton, deuteron and alpha at variable energy from 10 to $45 \mathrm{MeV}$ (Figure 1). Most of the applied uses of the beams focuses on materials studies and characterization. However, its properties give access to numerous radionuclides with potential applications especially for medical imaging. For example, in the period 2005-2013, ${ }^{211}$ At was produced once a week (300 MBq) (irradiation of target only, no radiochemistry made at Orléans) until the cyclotron ARRONAX (Nantes) was built and became operational to produce regular batch of this radionuclide for alpha-immunotherapy [5-8]. In a general context of the development of radiometals, such possibilities appear to be very interesting for accessing exotic radionuclides. The production of a radionuclide needs not only to perform a nuclear reaction but also to separate the radionuclide of interest from a bulk target. For this purpose, the 
cyclotron of Orléans is of interest in producing radionuclides for analytical applications allowing for the validation of the separation by the radiotracer method [9] and a method as sensitive as Inductively Coupled Plasma-Mass Spectrometry (ICP-MS). In this context, it was necessary to initiate tools and methodology in radiochemistry to develop further the accelerator in the area of medical radionuclides. However, two constraints relative to the choice of radionuclides were met at the cyclotron of Orléans. The first constraint was to produce gamma emission and the second was that the half-life of the radionuclide produced must be below 100 days (due to nuclear waste management considerations). Hence for the following work, we used ${ }^{165} \mathrm{Er} / \mathrm{Er},{ }^{166} \mathrm{Ho} / \mathrm{Ho},{ }^{51} \mathrm{Cr} / \mathrm{Cr}$ and ${ }^{52} \mathrm{Mn} / \mathrm{Mn}$. Other tools to improve radiochemical separation based on resins, methodology, and target design must be developed. Two cases hereafter illustrate the method's development for the production and subsequent separation of ${ }^{165} \mathrm{Er}$ and ${ }^{52} \mathrm{Mn}$.

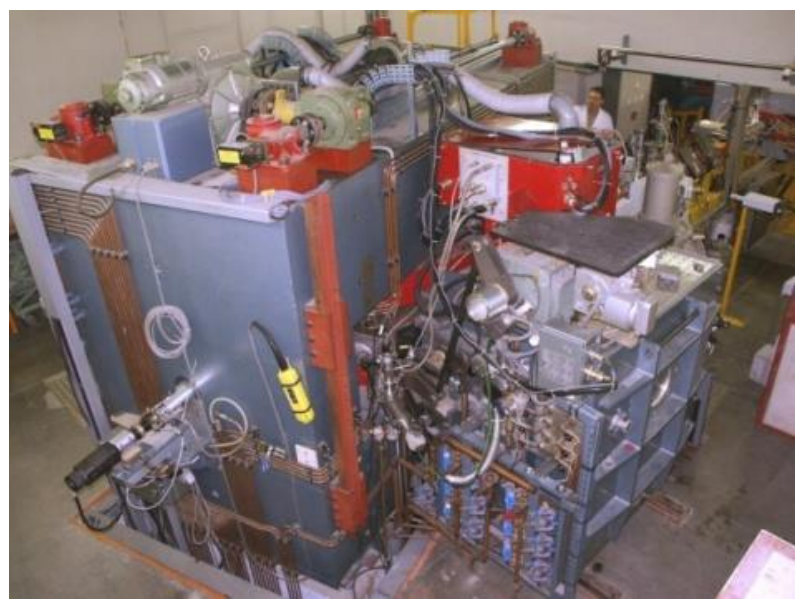

Figure 1. The cyclotron of Orléans.

A task of the radiochemist is to define the conditions of separation of two elements: including resin, eluent (simple and compatible with the radiolabeling process) and the methodology (radiotracer method, irradiation conditions). These aspects have been developed during the production of ${ }^{165} \mathrm{Er}$. Difficulties were the separation of two adjacent lanthanides in disproportionate quantities and a separation compatible with the radiolabeling of molecules. ${ }^{165}$ Er decays with electron capture without gamma-ray emission, producing only X-rays (47-55 keV with a cumulative intensity of 73.7\%) [10]. It is an ideal radionuclide for Auger electron therapy [11] and can be used for bimodality Magnetic Resonance Imaging / Single Photon Emission Computed Tomography (MRI/SPECT) [12]. It is accessible by irradiation of a natural Ho target by a proton or deuteron beam [13,14]. Its half-life of $\mathrm{T}_{1 / 2}=10.36 \mathrm{~h}$ is compatible with radiolabeling of small molecules. To access ${ }^{165} \mathrm{Er}$, irradiation with proton and deuteron beam has been used. The conditions of separation of Er/Ho have been defined by determination of weight coefficients (Dw). Tests on a small column $(2 \mathrm{~mL}$ ) have been performed to validated elution parameters. First tests on semi-automation of the separation have been made to allow manipulation of more than $100 \mathrm{MBq}$ of ${ }^{165} \mathrm{Er}$. The ratio ${ }^{166+\text { nat }} \mathrm{Ho} /{ }^{165} \mathrm{Er}$ has been determined to evaluate the efficiency of separation.

The access to the desired radionuclide might in some cases be challenging due to the irradiation path rather than to the radiochemical separation. Design of the target then becomes the key point. This is the case for ${ }^{52} \mathrm{Mn}$. It has a low average energy in $\beta+$ and its range in biological tissues (244.6 keV, $0.63 \mathrm{~mm})$ [15] is comparable to ${ }^{18} \mathrm{~F}(250 \mathrm{keV}, 0.62 \mathrm{~mm})$ [16,17]. These values are better than those of ${ }^{51} \mathrm{Mn}(970.2 \mathrm{kev}, 4.275 \mathrm{~mm})$ in terms of Positron Emission Tomography (PET) resolution (ratio of 6). In addition, the short half-life of ${ }^{51} \mathrm{Mn}\left(\mathrm{T}_{1 / 2}=46.2 \mathrm{~m}\right.$.) requires working with high activities to optimize radiochemical separations. Finally, the need to use enriched targets in ${ }^{50} \mathrm{Cr}$ or ${ }^{54} \mathrm{Fe}$ in case of ${ }^{51} \mathrm{Mn}$ is a real obstacle. In first approach, to the implementation of radiolabeling studies, ${ }^{52} \mathrm{Mn}\left(\mathrm{T}_{1 / 2}=5.59\right.$ days $)$ 
has been suggested for the diagnosis and treatment of blood diseases [18], as a cationic perfusion tracer [19], and for the study of the involvement of manganese in the pathophysiology of degenerative neurological diseases [20]. To perform the first irradiations to determine Dw, according to the literature, irradiation of a target of $\mathrm{Cr}$ is necessary. Foil of $\mathrm{Cr}$ does not exist with convenient dimensions allowing direct irradiation to obtain ${ }^{52} \mathrm{Mn}$. Therefore, we have designed a target of $\mathrm{Cr}$ using powder of chromium.

\section{Materials and Methods}

\subsection{Materials}

All irradiations were made at the cyclotron of Orléans (a CGR-MeV 680 Type [21-25], (Figure 1) in a targetry named "hatch tip" (Figure 2) for the experiments presented in this work.

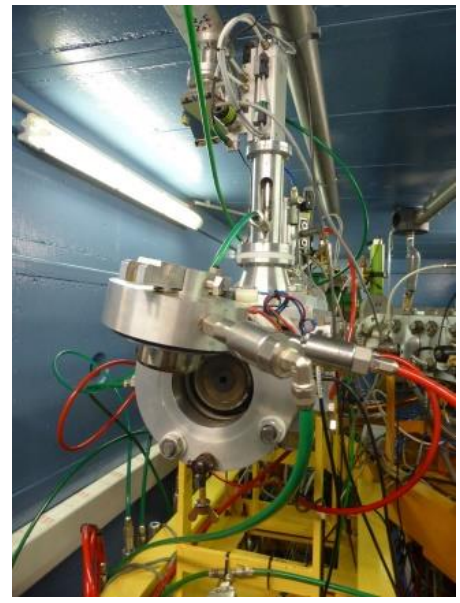

Figure 2. Targetry "hatch tip" low current $(<2 \mu \mathrm{A})$ for development.

Ho and $\mathrm{Cr}$ elements were used to product various radionuclides. Commercial (Alfa Aesar) high purity foil of Ho (purity: 99.9\%; thickness: 127 and $300 \mu \mathrm{m}$ ) was used. As commercial high purity chromium foil is not available with a thickness less than $500 \mu \mathrm{m}$ without polymer support, chromium sample were made by sintering of high purity chromium powder (99\%, 100 mesh metal basis density $=2.0-3.0 \mathrm{~g} / \mathrm{cm}^{2}$ ). The chromium powder was pressed to obtain $13 \mathrm{~mm}$ (outer diameter) pellets.

Nitric acid (67-69\%; SCP Science Plasma Pure; Fisher Scientific), hydrochloric acid (32-35\%; SCP Science; Fisher Scientific), alcohol ethanolic (Fisher Chemical), AG1 $88^{\circledR}$ resin anion exchange (200-400 mesh) (Bio-Rad Laboratories) and LN2 resin (Triskem). A small column in $2 \mathrm{~mL}$ polypropylene $(\mathrm{PP})$ including frits (pore size $=20 \mu \mathrm{m})(\mathrm{PE}$ : polyethylene) was used with internal diameter: $7 \mathrm{~mm}$ and a filling height of resin $>39 \mathrm{~mm}$, reference AC-142-TK from Triskem. All water used for the dilutions had a resistivity of $18 \mathrm{M} \Omega$ and was prepared using Purelab (Veolia) (Ultrapure Water Purification System).

Activated samples were diluted and put in a tube in a determinated geometry. Activity measurements were assessed by $\gamma$-ray spectrometry with an HPGe (High-Purity Germanium) detector. The HPGe detector was calibrated in energy and efficiency for different geometries with certified standard radioactive sources (Cerca, France). For activity measurement, $\gamma$-ray spectrum analysis software package, Genie 2000 (Canberra, France) was used. The concentrations of Er Ho, Cr and Mn were estimated following peaks centered at $53 \mathrm{keV}$ for ${ }^{165} \mathrm{Er}, 80 \mathrm{keV}$ for ${ }^{166} \mathrm{Ho}, 320 \mathrm{kev}$ for ${ }^{51} \mathrm{Cr}$ and 935 for ${ }^{52} \mathrm{Mn}$ (744 and 1434 can be used too). All activities were determined at the end of beam (EOB).

For polishing the chromium target, Model ES 300GTL has been used. The magnetic putty $(1,3$ and $6 \mu \mathrm{m}$ ) carpet for pre-polishing (graduation 120, 320, 600 and 1200) and carpet for polishing $(1,3$ and $6 \mu \mathrm{m}$ ) came from ESCIL (France). 


\subsection{Methods for ${ }^{165}$ Er (an Emitter Auger Electron and Bimodality)}

\subsubsection{Irradiation}

${ }^{165} \mathrm{Er}$ has been the subject of some publications concerning various methods of production from a cyclotron or a neutron reactor. The neutron pathway leads to a very large range of activities but the result is "carrier added" (i.e., the presence of other isotopes of erbium). However, a ligand radiolabeling application has to be a "no carrier added" pathway. Therefore, irradiation with a cyclotron, starting from a different element, can be more interesting.

Irradiation of an erbium target (natural or enriched) by a proton beam will be according to the reactions: ${ }^{\text {nat }} \operatorname{Er}(\mathrm{p}, \mathrm{xn}){ }^{165} \mathrm{Tm} \rightarrow$ (by decay) ${ }^{165} \operatorname{Er}$ or ${ }^{\text {nat }} \operatorname{Er}(\mathrm{d}, \mathrm{xn}){ }^{165} \mathrm{Tm} \rightarrow{ }^{165} \operatorname{Er}$ [25]. The irradiation of this natural target will lead to ${ }^{165} \mathrm{Tm}(30.06 \mathrm{~h})$ but also to ${ }^{167} \mathrm{Tm}\left(\mathrm{T} \frac{1}{2}=9.25\right.$ days $)$ and ${ }^{168} \mathrm{Tm}$ ( $\mathrm{T} \frac{1}{2}=93.1$ days). Indeed, the percentage (\%) of every isotope on natural erbium is $0.139,1.601,33.503$, $22.869,26.978$ and 14.910 respectively to isotope 162, 164, 166, 167, 168 and 170 of erbium.

To overcome this, the irradiation of a ${ }^{166}$ Er enriched target guarantees a single nuclear reaction such as: ${ }^{166} \operatorname{Er}(p, 2 n){ }^{165} \mathrm{Tm}$ which is quite challenging as it is not an easy and cheap way to obtain ${ }^{165}$ Er for proof of concept.

The "easiest" way to access to ${ }^{165} \mathrm{Er}$ is the irradiation of a natural holmium target by proton beam according to the nuclear reaction ${ }^{165} \mathrm{Ho}(\mathrm{p}, \mathrm{n}){ }^{165} \mathrm{Er}$ at $16 \mathrm{MeV}$ or deuteron beam by ${ }^{165} \mathrm{Ho}(\mathrm{d}, 2 \mathrm{n}){ }^{165} \mathrm{Er}$ at $17.5 \mathrm{MeV}$. The proton beam method can be exploited in a commercial cyclotron (less than $20 \mathrm{MeV}$ ). At the cyclotron of Orléans, two ways of production have been explored. All cross sections were known and obtained by irradiation or simulation from calculation codes (ALICE-IPPE) $[12,13,26,27]$.

The ratio ${ }^{165} \mathrm{Er} /{ }^{166} \mathrm{Ho}$ produced by proton and deuteron beam is respectively of around $400 / 1$ and $8 / 1$. The origin of the production of ${ }^{166} \mathrm{Ho}$ by proton irradiation is not clearly identified, but neutron activation seems to be the source.

\subsubsection{Separation ${ }^{165} \mathrm{Er} /{ }^{166} \mathrm{Ho}$}

The major difficulty in the development of ${ }^{165} \mathrm{Er}$ is its extraction from the holmium target. The selectivity factor for the couple Ho/Er (SF: Separation Factor around 1.5) is amongst the lowest in the lanthanides. In all publications relative to the irradiation of a Ho target, only one evokes a treatment of this target by a separation of the Ho/Er [11] pair. The complexing agent, $\alpha$-HIBA (alpha-HydroxyIsoButyric Acid) is widely used in the separation of lanthanides [28]. However, these separations are often made at the analytical level with the use of an online chromatographic system (High-Performance Liquid Chromatography (HPLC)) on balanced mixtures or traces (some ng or pg) for each lanthanide. To separate a few ng of ${ }^{165} \mathrm{Er}$ from of few $\mathrm{mg}$ of a target of about $200 \mathrm{mg}$ of natural holmium becomes more complex. In addition, the separation conditions must allow the use of ${ }^{165} \mathrm{Er}$ in radiolabeling of ligands aiming vectorised therapy with Auger electron or used in radiotracer for biomodality MRI/SPECT.

HDEHP (di(2-ethylhexyl) phosphoric acid), HEHEHP (mono-2-ethylhexyl ester of phosphonic acid) and (H[DTMPeP]) bis(2,4,4-trimethylpentyl) phosphinic acid are the main acidic organophosphorous extractants [29] used in Rare Earth Element (REE) separation processes and have also been commercialized (for Triskem commercial name: LN, LN2 and LN3). HDEHP has been widely used for primary separation because the distribution coefficients of the REEs as a group differ markedly from impurities in leach groups (e.g., in spent fuel actinides and REEs) [30]. For this project, LN2 resin (Triskem) based on (HEHEHP) was used. This reagent was chosen because REEs can be stripped at lower acidities than from HDEHP [31]. They were used for the separation of adjacent lanthanides including the separation of a microcomponent from a macrocomponent [32-34]. Weight coefficients Dw have been determined for various concentrations of $\mathrm{HNO}_{3}$. Additional evaluation of these coefficients on LN2 resin was performed with higher ${ }^{166} \mathrm{Ho}$ activity using deuteron irradiation, which should allow more sensitivity. The results presented here are part of a more complete study about $\mathrm{Ho} / \mathrm{Er}$ with comparison LN, LN2 and LN3 (in the case of LN3, it is necessary to use a low concentration 
of $\mathrm{HNO}_{3}$ ). The main drawbacks of HDEHP (LN) is a low adjacent separation factor, relatively low acidity for REE stripping, as well as low hydrolytic stability [35]. Phosphonic and phosphinic acids are more hydrolytically stable and effective extractants when compare with HDEHP. Moreover, they have demonstrated a high selectivity for the "heavy"REE (hREEs) compared to "light"REE (lREEs) [29].

For determination of distribution coefficient Dw, a target of natural Ho of $0.3 \mathrm{~mm}$ of thickness $\left(196 \mathrm{mg}\right.$ ) was irradiated during $2 \mathrm{~h}$ at $2 \mu \mathrm{A}$ at $17.5 \mathrm{Mev}$ deuterons ( $\mathrm{A}_{\mathrm{EOB}}$ : Activity (EOB)): around $700 \mathrm{MBq}$ of ${ }^{165} \mathrm{Er} / 90 \mathrm{MBq}$ of ${ }^{166} \mathrm{Ho}$ were produced then dissolved in $1 \mathrm{~mL}$ of $5 \mathrm{M} \mathrm{HNO}_{3}$ solution (no cut target for batch tests) and after that the complete dissolution of the target, adjusted to $5.5 \mathrm{~mL}$ with $18 \mathrm{M} \Omega$ water. This solution of $0.9 \mathrm{M} \mathrm{HNO}_{3}$ was the crude solution (concentration around $35 \mathrm{mg} / \mathrm{mL}$ of holmium and $13 \mathrm{MBq}$ of ${ }^{165} \mathrm{Er} / 1.6 \mathrm{MBq}$ of ${ }^{166} \mathrm{Ho}$ ). Around $100 \mathrm{mg}$ of LN2 resin was weighed for each test, which was always done in triplicate. In every tube, LN2 resin was mixed with $100 \mu \mathrm{L}$ of crude solution and volume was adjusted to $1.5 \mathrm{~mL}$ with different volumes of $\mathrm{HNO}_{3}$ and water $18 \mathrm{M} \Omega$ to obtain the final concentration of $\mathrm{HNO}_{3}$.

For example, at $0.5 \mathrm{M} \mathrm{HNO}_{3}, 650 \mu \mathrm{L}$ of $1 \mathrm{M} \mathrm{HNO}_{3}$ and $750 \mu \mathrm{L}$ of $18 \mathrm{M} \Omega$ water were added to $100 \mu \mathrm{L}$ of crude solution of ${ }^{165} \mathrm{Er} /{ }^{166} \mathrm{Ho}$ (initial concentration $0.9 \mathrm{M} \mathrm{HNO}_{3}$ ). Every tube was shaken for $30 \mathrm{~min}[36,37]$ then allowed to rest and centrifuged for $20 \mathrm{~min} .500 \mu \mathrm{L}$ of each solution were extracted and diluted to $2 \mathrm{~mL}$ by adding $1.5 \mathrm{~mL} 18 \mathrm{M} \Omega$ water (geometry called as "Tube $2 \mathrm{G}^{\text {"). }}$. Then samples were measured at spectrometry $\gamma$ in this defined geometry with acceptable dead time $(<5 \%)$. For several tubes, it was necessary to allow for one to two days of decay to perform a measurement.

Capacity of LN2 resin adsorption is $0.16 \mathrm{mmol} / \mathrm{mL}$ : maximum of $26.4 \mathrm{mg}$ of holmium can be used for $0.37 \mathrm{~g}$ of resin $(1 \mathrm{~mL})$. However, Triskem recommends a surety factor of $50 \%$ on the capacity of adsorption. For that, in all batch tests $100 \mu \mathrm{L}$ of crude solution contained around $3.5 \mathrm{mg}$ of natural Ho. In a concentration of $0.4 \mathrm{M} \mathrm{HNO}_{3}$, two tests (denote 0.4100 and 0.4200 ) with $100 \%$ and $200 \%$ capacity of resin had added, respectively with 200 and $400 \mu \mathrm{L}$ of crude solution to evaluate this factor on values $D_{w}$ and $S F$.

Weight distribution $\mathrm{D}_{\mathrm{w}}(\mathrm{mL} / \mathrm{g})$ and separation factor $\left(\mathrm{SF}_{\mathrm{Er} / \mathrm{Ho}}\right)$ were calculated using the following equation:

$$
D_{w}=\frac{A_{0}-A_{e}}{A_{e}} \times \frac{V}{m}
$$

Here $\mathrm{A}_{0}$ and $\mathrm{A}_{\mathrm{e}}$ are the liquid phase metal activities $(\mathrm{Bq})$ before and after equilibrium, $m$ is the weight of the LN2 resin in grams and V is the volume of liquid phase in $\mathrm{mL}$.

$$
S F_{E r / H o}=\frac{D_{w}(E r)}{D_{w}(H o)}
$$

Then tests on a $2 \mathrm{~mL}$ column with around $0.37 \mathrm{~g}$ of LN2 resin $(1 \mathrm{~mL})$ were made first by the gravimetry method then with variation of flow $(1 \mathrm{~mL} / \mathrm{min}$ and $3 \mathrm{~mL} / \mathrm{min})$ at atmospheric pressure using a peristaltic pump in the outlet of the column. A gradient of concentration on $\mathrm{HNO}_{3}$ was used: $0.4 \mathrm{M} 0.8 \mathrm{M}, 1 \mathrm{M}$ and $2 \mathrm{M}$ or/and $5 \mathrm{M}$ if necessary. Tests at 1 bar of Nitrogen (maximum pressure of solenoid valves from Bio-Chem (used in semi-automated system) is 1.4 bars) were made. Around $4 \mathrm{~g}$ of LN2 (for a maximum of mass target of $140 \mathrm{mg}$, around $11 \mathrm{~mL}$ ) 50-90 mg of the target were used in semi-automated tests. Four tests on a homemade automation system (drive with the homemade software ACCRA (Automatisme \& Contrôle Commande Radiochimie)) were made using the remote control sketch below (Figure 3) from the dissolution step of the target until the final evaporation step of $\mathrm{HNO}_{3}$. 


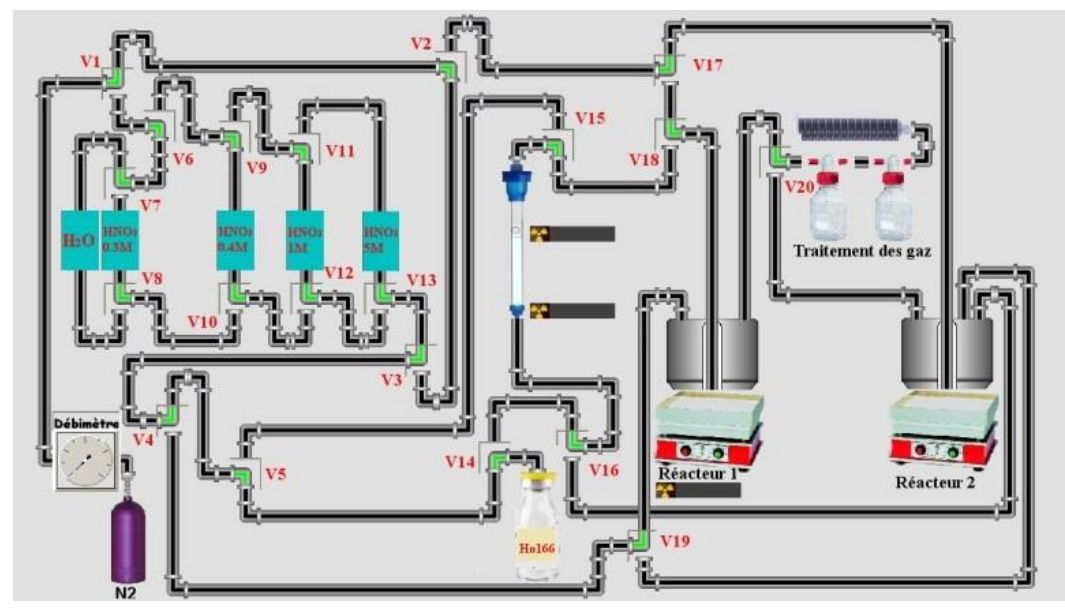

Figure 3. Remote control of Er/Ho separation.

In a semi-automated system $50 \mu \mathrm{L}$ of solution were collected manually to determine the extraction yield of radionuclide in each test after adding $2 \mathrm{~mL}$ of $0.3 \mathrm{M} \mathrm{HNO}_{3}$ in the reactor. The reactor was weighed before and after addition of $0.3 \mathrm{M} \mathrm{HNO}_{3}$ (no weighing for test $\mathrm{n}^{\circ} 3$ : no extraction yield). This was the activity reference for ${ }^{165} \mathrm{Er}$ and ${ }^{166} \mathrm{Ho}\left(\mathrm{A}_{\text {ref }}\right.$ : deposited activity). With these values, the initial activity of ${ }^{165} \mathrm{Er}$ and ${ }^{166} \mathrm{Ho}$ in the cut target were determined. A relationship activity-weight was established by the ratio ${ }^{165} \mathrm{Ho} /{ }^{166} \mathrm{Ho}$ : activity of ${ }^{166} \mathrm{Ho}$ in $\mathrm{Bq}$ by $\mathrm{mg}$ of ${ }^{165} \mathrm{Ho}$ (cut target). the initial ratio $\mathrm{Ho} /{ }^{165} \mathrm{Er}$ (for Ho, ${ }^{165} \mathrm{Ho}$ was considered because the mass of ${ }^{166} \mathrm{Ho}$ was insignificant) on the target (cut target mass) and the ratio in an isolated fraction of ${ }^{165} \mathrm{Er}$ was calculated. A Ho decontamination factor was determined according to the following formula:

$$
F_{H o(\text { cont. })}=\frac{A_{0(H o)}^{166} / A c t_{f(H o)}^{166}}{A_{0(E r)}^{165} / A_{f(E r)}^{165}}
$$

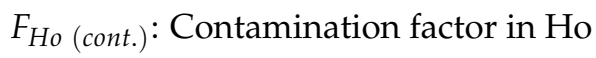

$A_{0(\mathrm{Ho})}^{166}:$ Activity ${ }^{166} \mathrm{Ho}$ in cut target

$A_{f(\mathrm{Ho})}^{166}$ : Activity ${ }^{166} \mathrm{Ho}$ in isolated fraction of ${ }^{165} \mathrm{Er}$

$A_{0(E r)}^{165}$ : Activity ${ }^{165} \mathrm{Er}$ in cut target

$A_{f(E r)}^{165}:$ Activity ${ }^{165} \mathrm{Er}$ in isolated fraction of ${ }^{165} \mathrm{Er}$

All dilution factors were determined by weighing aliquots of fraction. A geometry "Tube 2G" was used to determine the activities of the samples. Extraction yield (\%) was defined as:

$$
Y(\%)=\frac{\sum \text { Activities all tubes }}{A_{\text {ref }}}
$$

$\sum$ Activities all tubes: sum of all activities in fraction tubes for one radionuclide $\left({ }^{166} \mathrm{Ho}\right.$ or $\left.{ }^{165} \mathrm{Er}\right)$ $\mathrm{A}_{\text {ref: }}$ deposited activity on column.

The same column was used and between different tests (4), column is conditioned with $30 \mathrm{~mL}$ of $5 \mathrm{M} \mathrm{HNO}_{3}$ then $18 \mathrm{M} \Omega$ water until $\mathrm{pH}$ was neutral. Then, $30 \mathrm{~mL}$ of $0.3 \mathrm{M} \mathrm{HNO}_{3}$ was used to conditioning column. Manually target was cut and around 50\% of target was dissolved (more than $90 \%$ of activity of target). All weights listed for the target were referenced to cut the target (not all the irradiated mass of the target). The height of the column (glass) was $14 \mathrm{~cm}$ and the inner diameter $1 \mathrm{~cm}$. The LN2 resin was shaken for $30 \mathrm{~min}$ with $18 \mathrm{M} \Omega$ water then put on the column. It was conditioned 
with $20 \mathrm{~mL}$ of $18 \mathrm{M} \Omega$ water then $30 \mathrm{~mL}$ of $0.3 \mathrm{M} \mathrm{HNO}_{3}$ before depositing the sample. Then, the cut target was dissolved in $1 \mathrm{~mL}$ of $5 \mathrm{M} \mathrm{HNO}_{3}$ in a reactor of $3 \mathrm{~mL}$. Nitric acid was evaporated until it was in a pink gel formation. Then $2 \mathrm{~mL}$ of $0.3 \mathrm{M} \mathrm{HNO}_{3}$ was added to dissolve the pink residue and transfer it to the column under flow of nitrogen $(20 \mathrm{~mL} / \mathrm{min})$. The solution on top of column was adsorbed under the flow of nitrogen $(100 \mathrm{~mL} / \mathrm{min})$. When the solution on top of the column was adsorbed, $0.4 \mathrm{M} \mathrm{HNO}_{3}(100-120 \mathrm{~mL})$ was used to elute Ho at flow of 1-2 drops $/ \mathrm{s}(1 \mathrm{~mL} / \mathrm{min})$ under 1 bar of Nitrogen (at flow of $100 \mathrm{~mL} / \mathrm{min}$ ). Then $1 \mathrm{M} \mathrm{HNO}_{3}$ was used (around $40 \mathrm{~mL}$ except for sample 3 $(22 \mathrm{~mL})$ ) and finally, in some cases, $2 \mathrm{M}\left(15 \mathrm{~mL}\right.$ for sample 3) and $5 \mathrm{M} \mathrm{HNO}_{3}$ (sample 1 and 3) more to elute residue activity on the column. The radiotracer method was used for this separation using ${ }^{166} \mathrm{Ho}$ for Ho and ${ }^{165} \mathrm{Er}$ for Er.

\subsection{Methods for ${ }^{52} \mathrm{Mn}$ (Radioimmunotherapy and Bimodality)}

To obtain this radionuclide from a cyclotron, the irradiation of chromium by a proton beam is the most used route, by the reaction ${ }^{52} \mathrm{Cr}(\mathrm{p}, \mathrm{n})^{52} \mathrm{Mn}$ to $16-17 \mathrm{MeV}$ [38], because it is also the most accessible by commercial cyclotrons. Then, the separation of ${ }^{52} \mathrm{Mn}$ from a chromium target was carried out by liquid-liquid extraction [39], but the most interesting results concern the use of an ion exchange resin $[40,41]$. This route seems more suitable for subsequent automation of the separation step. The choice of the best way to access ${ }^{52} \mathrm{Mn}$ must be focused in part on the simplicity of the separation process. Indeed, because of its three high gamma rays with an emission of more than $90 \%$, the radiation safety for operators is a paramount criterion. Here, a target design (Cr pellet) is described in detail. Various studies have been made to validate the specifications of a pellet of chromium for irradiation.

As chromium is a compound that oxidizes very easily with air, the sintering of $\mathrm{Cr}$ powder has to be done in an inert or reducing atmosphere in an electrical furnace (Nabertherm with controller P 320). Therefore, we used an $\mathrm{H}_{2} / \mathrm{N}_{2}$ mixture (5\% hydrogen). In addition, to ensure that the chromium does not react with the residual oxygen, we surrounded it with crushed graphite. We placed the whole in an alumina crucible (Figure 4 ):

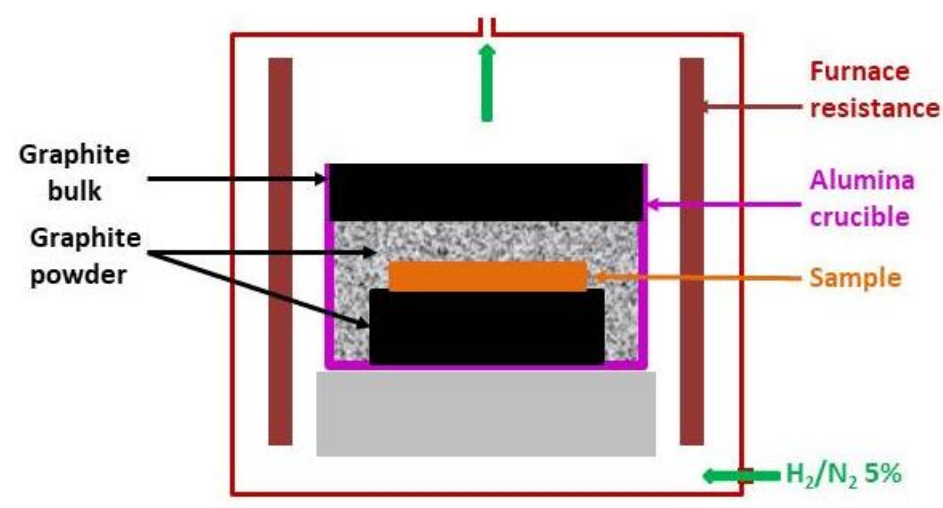

Figure 4. Set-up of sintering.

Finally, we proceeded to the heat treatment with the following thermal cycle:

- Temperature rise rate: $5^{\circ} \mathrm{C} \cdot \mathrm{min}^{-1}$

- Isothermal run time, $30 \mathrm{~min}$

- Cooling speed: $5{ }^{\circ} \mathrm{C} \cdot \min$

The same program was used in vacuum conditions. The vacuum was $10^{-7} \mathrm{mBar}$ and the furnace is a homemade system where the measurement of temperature is determined by pyrometry. The sample was put on a block next to a block of molybdenum. By measuring the emissivity of molybdenum, the temperature of the sample was determined. 
After sintering, $\mathrm{Cr}$ pellets were tested in bending conditions (to determine stress resistance of pellet). The device used was unconventional and inspired by the "Ball on ring" test (Figure 5). A moving speed $(0.5 \mathrm{~mm} / \mathrm{min})$ of a ball of alumina $(9.32 \mathrm{~mm}$ diameter $)$ was applied. The measurement stops when the target broke. To compare mechanical properties in bending conditions of each $\mathrm{Cr}$ pellet, we compared the load required to break the pellet.

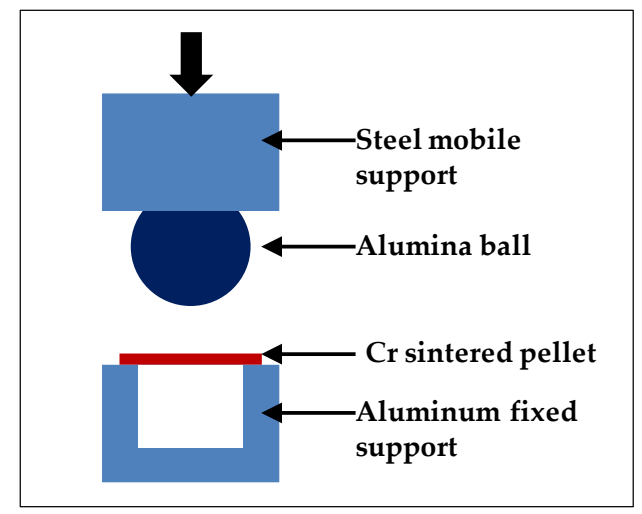

Figure 5. Bending test.

Using a target of $\mathrm{Cr}$ designed (800 $\mathrm{mg}$ pressed at 8.3 tons and sintered $1 \mathrm{~h}$ at $800{ }^{\circ} \mathrm{C}$ ), a first determination of $\mathrm{Dw}$ for separation $\mathrm{Cr} / \mathrm{Mn}$ was done. The radiotracer method was used to follow two elements ${ }^{51} \mathrm{Cr}$ for $\mathrm{Cr}$ and ${ }^{52} \mathrm{Mn}$ for $\mathrm{Mn}$. To obtain a significant activity of ${ }^{51} \mathrm{Cr}$, irradiation of the $\mathrm{Cr}$ pellet was performed at $23 \mathrm{MeV}$. In these experimental conditions, nuclear reactions ${ }^{\text {nat }} \mathrm{Cr}(\mathrm{p}, \mathrm{n})^{52} \mathrm{Mn}$ and ${ }^{\text {nat }} \mathrm{Cr}(\mathrm{p}, \mathrm{x})^{51} \mathrm{Cr}$ occurred.

For the resin exchange anions, the $\mathrm{AG} 1 \times 8^{\circledR}$ resin was used and different concentrations of $\mathrm{HCl}(1$, 4,8 and $12 \mathrm{M}$ ) and various percentages of Ethanol ( 0 and 93 to $98 \%$ by step of $1 \%$ ) in eluted solution (ethanol/ $\mathrm{HCl}$ ) were tested. Contact time was $1 \mathrm{~h}$ instead of several hours reference studies [14,40].

Briefly, a Cr pellet of around $800 \mu \mathrm{m}$ of thickness $(800 \mathrm{mg})$ was irradiated during $0.5 \mathrm{~h}$ at $0.2 \mu \mathrm{A}$ (EOI: around $2.9 \mathrm{MBq}$ of ${ }^{52} \mathrm{Mn} / 1.45 \mathrm{MBq}$ of ${ }^{51} \mathrm{Cr}$ ). The target was dissolved in $5 \mathrm{~mL}$ of $12 \mathrm{M}$ $\mathrm{HCl}$ and evaporated to dryness. Then, we dissolved the residue with $2 \mathrm{~mL} 2 \mathrm{M} \mathrm{HCl}$. This was the crude solution of ${ }^{52} \mathrm{Mn} /{ }^{51} \mathrm{Cr}$. Around $80 \mathrm{mg}$ of $\mathrm{AG} 1 \times 8^{\circledR}$ resin were weighed for each test (all tests were triplicated). In every tube, AG1x8 ${ }^{\circledR}$ resin was mixed with $970 \mu \mathrm{L}$ of elution solution. Then $30 \mu \mathrm{L}$ of crude solution was added. Every tube was shaken for $1 \mathrm{~h}$ then allowed to rest, and finally centrifuged for $10 \mathrm{~min} .500 \mu \mathrm{L}$ of each solution were extracted and diluted to $2 \mathrm{~mL}$ by adding $1.5 \mathrm{~mL} 18 \mathrm{M} \Omega$ water. Then samples were measured at spectrometry $\gamma$ in this geometry called "Tube 2G" with acceptable dead time. For several tubes, it was necessary to allow for one to two days of decay to perform a measurement. All calculations were made according to Equations (1) and (2) in Section 2.2.2. Separation ${ }^{165} \mathrm{Er} /{ }^{166} \mathrm{Ho}$.

For a test of the semi-automation of $\mathrm{Cr} / \mathrm{Mn}$ separation, a $1.2 \mathrm{~mL}$ of dissolved chromium solution (eluent 1: Ethanol/HCl 12 M (97/3)) was used. No calculations of a decontamination Cr factor were done. This aliquot which contained $35,000 \mathrm{~Bq}$ of ${ }^{51} \mathrm{Cr}$ and $3100 \mathrm{~Bq}$ of ${ }^{52} \mathrm{Mn}$, was deposited on column 1. Three columns with 300,200 and $100 \mathrm{mg}$ of $\mathrm{AG} 1 \times 8^{\circledR}$ resin were used, respectively, as columns 1,2 and 3. The sample was deposited on column (all have been conditioned with $10 \mathrm{~mL}$ of water $18 \mathrm{M} \Omega$, then $10 \mathrm{~mL}$ ethanol and finally $10 \mathrm{~mL}$ of eluent 1 ). Column 1 was eluted first with $8 \mathrm{~mL}$ of eluent 1 then rinsed with $10 \mathrm{~mL}$ of eluent 1 divided into 3 fractions of $3 \mathrm{~mL}$. Finally $1 \mathrm{~mL}$ of $\mathrm{HCl} 12 \mathrm{M}$ was used to recover ${ }^{52} \mathrm{Mn}$. An aliquot of this fraction was used to quantify ${ }^{51} \mathrm{Cr}$ and ${ }^{52} \mathrm{Mn}$. $30 \mathrm{~mL}$ of pure ethanol were added and mixture was shaken $10 \mathrm{~min}$ then deposited on column 2 . After that, $3 \mathrm{~mL}$ of eluent was added and $1 \mathrm{~mL}$ of $\mathrm{HCl} 12 \mathrm{M}$ desorbed ${ }^{52} \mathrm{Mn}$. After collecting the fraction for measurements, $30 \mathrm{~mL}$ of pure ethanol was added and the batch shaken for $10 \mathrm{~min}$. The batch was adsorbed on column 3 and eluted with $3 \mathrm{~mL}$ of eluent 1 . Finally, ${ }^{52} \mathrm{Mn}$ was desorbed with $1.5 \mathrm{~mL}$ of $12 \mathrm{M} \mathrm{HCl}$. 
For optimizing this process and reducing the quantity of chromium, pre-polishing and polishing on the chromium target was made like this:

- Pre-polishing is necessary to reduce dramatically thickness of pellet:

- 30 min with carpet of 120 at $100 \mathrm{rpm}$;

- $8-10$ min with new carpet of 120 at $100 \mathrm{rpm}$.

Then, the thickness was checked because on following operations, every carpet decreased in thickness by about $100 \mu \mathrm{m}$ around:

- 5 min with carpet of 320 at $100 \mathrm{rpm}$;

- 10 min with carpet of 600 at $100 \mathrm{rpm}$;

- 20 min with carpet of 1200 at 100 rpm;

- Polishing:

- 30 min with carpet of $6 \mu \mathrm{m}$ at $100 \mathrm{rpm}$;

- $45 \mathrm{~min}$ with carpet of $3 \mu \mathrm{m}$ at $100 \mathrm{rpm}$;

- $45 \mathrm{~min}$ with carpet of $1 \mu \mathrm{m}$ at $100 \mathrm{rpm}$.

When illustrations showed polished samples, only the polishing step was taken.

Irradiation tests and separations were performed on unpolished targets.

\section{Results}

3.1. ${ }^{165} \mathrm{Er}$

Concentrations of $0.3 \mathrm{M}, 0.4 \mathrm{M}, 0.5 \mathrm{M}, 0.8 \mathrm{M}, 1 \mathrm{M}, 2 \mathrm{M}$ and $5 \mathrm{M} \mathrm{HNO}_{3}$ were evaluated for the separation at $50 \%$ of capacity adsorption of resin. They were also evaluated for concentration $0.4 \mathrm{M}$ $100 \%$ (point 0.4100 ) and 200\% (0.4 200) of capacity (Figure 6).

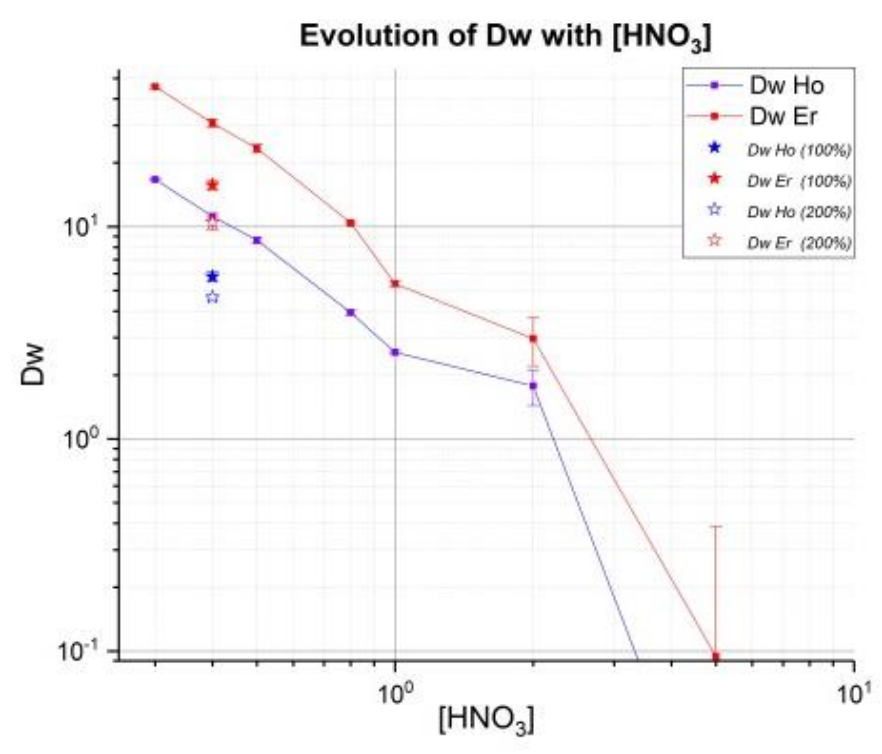

Figure 6. $\mathrm{D}_{\mathrm{w}}$ de Er/Ho with LN2. 
Weight distribution $\mathrm{D}_{\mathrm{w}}(\mathrm{mL} / \mathrm{g})$ and separation factor $\mathrm{SF}_{\mathrm{Er} / \mathrm{Ho}}$ was determined (Table 1):

Table 1. $\mathrm{D}_{\mathrm{w}}$ and SF of Er and $\mathrm{Ho}$ in $\mathrm{HNO}_{3}$.

\begin{tabular}{cccc}
\hline $\mathbf{H N O}_{3}$ & $\mathbf{D}_{\mathbf{w}}(\mathbf{E r})$ & $\mathbf{D}_{\mathbf{w}}(\mathbf{H o})$ & $\mathbf{S F}_{\mathbf{E r} / \mathbf{H o}}$ \\
\hline $0.3 \mathrm{M}$ & $45.7 \pm 1.3$ & $16.7 \pm 0.4$ & 2.74 \\
$0.4 \mathrm{M}$ & $30.8 \pm 2.0$ & $11.2 \pm 0.5$ & 2.75 \\
$0.4 \mathrm{M} \mathrm{100}$ & $15.4 \pm 1.2$ & $5.8 \pm 0.4$ & 2.70 \\
$0.4 \mathrm{M} 200$ & $10.5 \pm 1.1$ & $4.7 \pm 0.2$ & 2.25 \\
$0.5 \mathrm{M}$ & $23.4 \pm 1.5$ & $8.6 \pm 0.4$ & 2.71 \\
$0.8 \mathrm{M}$ & $10.4 \pm 0.2$ & $3.9 \pm 0.1$ & 2.65 \\
$1 \mathrm{M}$ & $5.4 \pm 0.2$ & $2.6 \pm 0.1$ & 2.11 \\
$2 \mathrm{M}$ & $3.0 \pm 1.0$ & $1.8 \pm 0.4$ & 1.67 \\
$5 \mathrm{M}$ & $0.1 \pm 0.4$ & $-0.4 \pm 0.3$ & -0.21 \\
\hline
\end{tabular}

There was no difference between $\mathrm{SF}_{\mathrm{Er} / \mathrm{Ho}}$ at 0.3 and $0.4 \mathrm{M} \mathrm{HNO}_{3}$ but Dw were high in the case of $0.3 \mathrm{M} \mathrm{HNO}_{3}$ : concentration for dissolution of target. Then, to start elution $0.4 \mathrm{M} \mathrm{HNO}_{3}$ can considered a better choice than $0.3 \mathrm{M} \mathrm{HNO}_{3}$. The separation factor was influenced by $\%$ of capacity resin involved in separation: at $200 \%$ of capacity, this factor SF decreased significantly and Dw was weaker. At this ratio, selectivity was low and a significant part of the erbium could be eluted with holmium. That is why some tests of elution on a $2 \mathrm{~mL}$ column were done with the following conditions: target dissolved in $0.3 \mathrm{M} \mathrm{HNO}_{3}$, starting elution of batch with $100-120 \mathrm{~mL} 0.4 \mathrm{M}$ or gradient with $0.4 \mathrm{M} / 0.8 \mathrm{M} \mathrm{HNO}_{3}$ before desorbing holmium with $1 \mathrm{M} \mathrm{HNO}_{3}$ and then erbium. If $1 \mathrm{M} \mathrm{HNO}_{3}$ was used directly, no separation was done, but using $0.4 \mathrm{M} \mathrm{HNO}_{3}$ generated a difference of elution between $\mathrm{Ho}$ and $\mathrm{Er}$ more important than the other eluent.

On a $2 \mathrm{~mL}$ column, by gravimetry, time elution was more than $1 \mathrm{~h}$ with $370 \mathrm{mg}$ of resin LN2. There was no influence of flow between $1 \mathrm{~mL} / \mathrm{min}$ and $3 \mathrm{~mL} / \mathrm{min}$ in separation only in separation time. At 1 bar of nitrogen, the flow was too quick and was reduced to $1 \mathrm{~mL} / \mathrm{min}$ in setting pressure of nitrogen to 0.7 bars.

With these previous tests, a semi-automated system of separation of Ho/Er was evaluated on a column of $4 \mathrm{~g}$ of LN2 resin (Table 2).

Table 2. Elution of 4 samples on semi-automated system separation of Er/Ho.

\begin{tabular}{|c|c|c|c|c|c|c|c|c|c|c|c|c|}
\hline \multirow[b]{2}{*}{ Sample } & \multicolumn{4}{|c|}{ Volume of Eluent (mL) } & \multicolumn{4}{|c|}{ Repartition of Ho (\%) } & \multicolumn{4}{|c|}{ Repartition of Er (\%) } \\
\hline & 1 & 2 & 3 & 4 & 1 & 2 & 3 & 4 & 1 & 2 & 3 & 4 \\
\hline $\mathrm{HNO}_{3} 0.4 \mathrm{M}$ & 102 & 104 & 123 & 110 & 87.9 & 82.4 & 90.9 & 89.6 & 1.5 & 0.5 & 0.0 & 1.6 \\
\hline $\mathrm{HNO}_{3} 1 \mathrm{M}$ & 45 & 38 & 22 & 38 & 12.1 & 17.6 & 9.0 & 10.4 & 98.5 & 99.6 & 24.3 & 98.4 \\
\hline $\mathrm{HNO}_{3} 2 \mathrm{M}$ & N.u. & N.u. & 15 & N.u. & - & - & 0.1 & - & & & 75.7 & \\
\hline $\mathrm{HNO}_{3} 5 \mathrm{M}$ & 45 & N.u. & 5 & N.u. & 0.0 & & 0.0 & & 0.0 & & 0.0 & \\
\hline
\end{tabular}

N.u.: Not used.

The isolated fraction in all samples (Table 3$)$ contained more than $60 \%(72.3 \pm 5.1 \%(n=4))$ of ${ }^{165}$ Er activity. 
Table 3. $\%$ of ${ }^{165} \mathrm{Er}$ and ${ }^{166} \mathrm{Ho}$ in isolated fraction against all fractions.

\begin{tabular}{ccccc}
\hline \multirow{2}{*}{ Sample } & \multicolumn{2}{c}{$\mathbf{H N O}_{3}$} & \multicolumn{2}{c}{ Isolated Fraction of ${ }^{\mathbf{1 6 5}} \mathbf{E r}$} \\
\cline { 2 - 5 } & Volume & Concentration & \multicolumn{2}{c}{ \% of $\mathbf{R n}$} \\
\cline { 2 - 5 } & $\mathbf{( m L )}$ & $\mathbf{( M )}$ & ${ }^{\mathbf{1 6 6}} \mathbf{H o}$ & ${ }^{\mathbf{1 6 5}} \mathbf{E r}$ \\
\hline $\mathbf{1}$ & 11 & 1 & 0.07 & 72.7 \\
$\mathbf{2}$ & 10 & 1 & 0.00 & 63.9 \\
$\mathbf{3}$ & 15 & 2 & 0.08 & 75.7 \\
$\mathbf{4}$ & 4 & 1 & 0.37 & 76.8 \\
\hline mean & & & 0.13 & 72.3 \\
$\boldsymbol{\sigma}$ & & & 0.14 & 5.1 \\
\hline
\end{tabular}

$\%$ of $\mathrm{Rn}$ : percentage of radionuclide in isolated fraction against all fractions.

The separation profile is illustrated in Figure 7 with the sample 3.

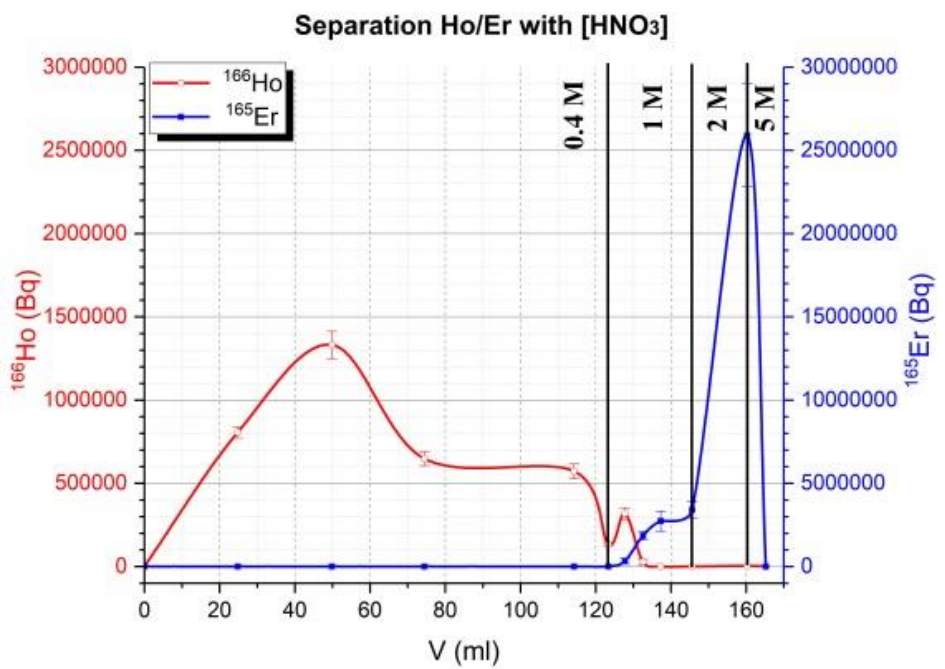

Figure 7. Profile of elution ${ }^{165} \mathrm{Er} /{ }^{166} \mathrm{Ho}$ of sample 3.

The extraction yields of erbium and holmium were higher than $90 \%$ (except sample 4 ). A Ho decontamination factor was calculated on sample 1, 2 and 4 (not possible for 3 because no reference activity $\mathrm{A}_{\text {ref }}$ (deposited activity on top of column)). The semi-automated separation system was significantly reduced quantity of holmium on isolated fraction of ${ }^{165} \mathrm{Er}$ by more than a factor $1294 \pm 1183(n=3)$ (Table 4).

Table 4. Analysis of isolated fraction from 4 tests on semi-automated separation system.

\begin{tabular}{|c|c|c|c|c|c|c|c|c|c|c|}
\hline \multirow{3}{*}{ Test } & \multirow{2}{*}{\multicolumn{2}{|c|}{$\begin{array}{c}\text { Extraction Yield } \\
\mathrm{Y}(\%)\end{array}$}} & \multicolumn{4}{|c|}{ Cut Target } & \multicolumn{3}{|c|}{ Isolated Fraction of ${ }^{165} \mathrm{Er}$} & \multirow{3}{*}{$\mathrm{F}_{\text {Ho (cont.) }}$} \\
\hline & & & \multirow{2}{*}{$\begin{array}{c}\text { Mass } \\
(\mathrm{mg})\end{array}$} & \multicolumn{2}{|c|}{ Activity (Bq) } & \multirow{2}{*}{$\begin{array}{c}\text { Ratio } \\
{ }^{165} \mathrm{Er} /{ }^{166} \mathrm{Ho}\end{array}$} & \multicolumn{2}{|c|}{ Activity (Bq) } & \multirow{2}{*}{$\begin{array}{c}\text { Ratio } \\
{ }^{165} \mathrm{Er} /{ }^{166} \mathrm{Ho}\end{array}$} & \\
\hline & ${ }^{166} \mathrm{Ho}$ & ${ }^{165} \mathrm{Er}$ & & ${ }^{166} \mathrm{Ho}$ & ${ }^{165} \mathrm{Er}$ & & ${ }^{166} \mathrm{Ho}$ & ${ }^{165} \mathrm{Er}$ & & \\
\hline 1 & 92 & 98 & 88.4 & $9.5 \times 10^{6}$ & $8.0 \times 10^{7}$ & 8.4 & $5.7 \times 10^{3}$ & $5.4 \times 10^{7}$ & 9397 & 1123 \\
\hline 2 & 95 & 98 & 57.4 & $6.3 \times 10^{6}$ & $5.2 \times 10^{7}$ & 8.3 & $1.4 \times 10^{3}$ & $3.0 \times 10^{7}$ & 21,070 & 2553 \\
\hline 3 & ND & ND & 53.8 & ND & ND & ND & $3.1 \times 10^{3}$ & $2.6 \times 10^{7}$ & 8356 & ND \\
\hline 4 & 86 & 86 & 74.7 & $8.3 \times 10^{6}$ & $7.2 \times 10^{7}$ & 8.6 & $1.7 \times 10^{3}$ & $3.0 \times 10^{7}$ & 1773 & 206 \\
\hline Mean & 91 & 94 & & & & 8.4 & & & 10,149 & 1294 \\
\hline$\sigma(n=3)$ & 5 & 7 & & & & 0.2 & & & $6950 *$ & 1183 \\
\hline
\end{tabular}




\subsubsection{Design Target Conception}

In order to obtain ${ }^{52} \mathrm{Mn}$, a natural chromium target was irradiated by a proton beam. Once irradiated, the target was then chemically treated to isolate ${ }^{52} \mathrm{Mn}$ from $\mathrm{Cr}$. However, the preparation of this target requires special attention. No commercial $\mathrm{Cr}$ foil exists with a thickness less than $500 \mu \mathrm{m}$ without polymer support. However, this element is commercially available in the form of powder. Because of the risks of cyclotron contamination, powdery targets are difficult to irradiate. A Cr pellet was therefore designed taking into account the following criteria: the risks of contamination during irradiation, dissolution of the target, limitation of the amount of chromium not activated in radiochemical separation (possibly through lower thickness). For these purposes, the physical aspects of the target such as mechanics, thermal resistance and porosity (closed and opened porosity) were studied.

\subsubsection{Compaction}

A study about optimization of parameters (force, mass and time of compaction of pellets) was made to obtain a pellet of $13 \mathrm{~mm}$ diameter with good visual mechanical resistance. First, a force of 8.3 tons was applied on the powder during $5 \mathrm{~min}$. Several quantities of powder were tested from 200 to $1200 \mathrm{mg}$ (Table 5). The aim was to obtain a complete pellet with a lower mass.

Table 5. Various mass of pellet of $\mathrm{Cr}$.

\begin{tabular}{ll}
\hline Powder (mg) & Description \\
\hline 200 & pellet incomplete \\
400 & pellet incomplete \\
& pellet incomplete \\
1200 & pellet perfect \\
\hline
\end{tabular}

Tests were carried out to reduce this mass (therefore the thickness) by varying time and compaction force. Results obtained are presented on the following Table 6. 
Table 6. different masses and thicknesses of the pellets.

\begin{tabular}{|c|c|c|c|c|}
\hline Force Tons (Bars) & Mass Powder (mg) & Time Compaction (min) & Thickness (mm) & Visual Aspect \\
\hline \multirow{4}{*}{$4(150)$} & 649.6 & 5 & 1.08 & $\mathrm{Bad}$ \\
\hline & 649.5 & 10 & 1.01 & Bad \\
\hline & 649.8 & 60 & 1.04 & Bad \\
\hline & 699.7 & 5 & 1.09 & $\mathrm{Bad}$ \\
\hline \multirow{9}{*}{$8.3(300)$} & $599.7(3) *$ & 5 & $0.89(3)$ & $\mathrm{Bad}$ \\
\hline & 600.2 & 30 & 0.84 & Good \\
\hline & $650.6(3) *$ & 2 & 0.88 & Good (2) ** \\
\hline & $650.8(2) *$ & 5 & 0.93 & Good \\
\hline & $650.2(4) *$ & 30 & 0.9 & Good \\
\hline & $650(2) *$ & 60 & 0.89 & $\mathrm{Bad}$ \\
\hline & $699.6(3) *$ & 2 & 0.96 & Good (2) ** \\
\hline & $699.4(3) *$ & 5 & 0.95 & Good \\
\hline & 700.2 & 60 & 1.04 & $\mathrm{Bad}$ \\
\hline
\end{tabular}

* () number of tests; ** () number of tests with described visual aspect.

Eleven pellets were made with better conditions of compaction, of $650 \mathrm{mg} 30 \mathrm{~min}$ at 8.3 tons (300 bars) with a good visual aspect and these were added to 4 obtained in first tests (Table 6). Thus a variability, was made among 15 pellets:

- $\quad$ weight average $649.6 \pm 0.6 \mathrm{mg}(15)$,

- $\quad$ thickness $=0.87 \pm 0.02 \mathrm{~mm}(13)$ ( 2 broken pellets by manipulating).

\subsubsection{Sintering}

Despite compaction, the pellets remained fragile. This was a problem for the irradiation as it means that in contact with a beam of high intensity, the pellet was likely to crumble or break. In order to improve the mechanical strength of the pellets, a study of sintering heat treatment was carried out on the pellet at various temperatures and different specific conditions of sintering (in air, vacuum and inert atmosphere).

The first tests were operated under atmosphere controls in oxygen $\left(500{ }^{\circ} \mathrm{C}\right.$ to $\left.1400{ }^{\circ} \mathrm{C}\right)$ (Figure 8). A bending test has been performed to check the flexural strength of the pellet. A load was applied, via a ball, to the center of the sample that would be biased in bending [42,43]. The force applied was recorded as a function of the vertical displacement of the ball. The tests were carried out on pellets of $800 \mathrm{mg}$ of compaction at 8.3 tons during $5 \mathrm{~min}$, sintered at $500^{\circ} \mathrm{C}, 800^{\circ} \mathrm{C}$ and $1000^{\circ} \mathrm{C}$ for $1 \mathrm{~h}$. Each test was repeated three times. Recording was stopped when the ball was cracked.

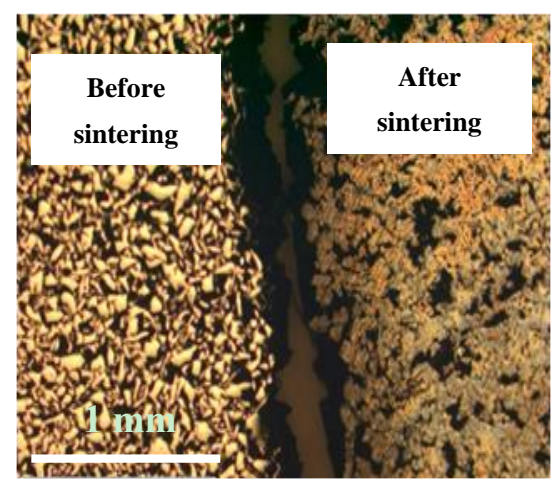

Figure 8. Micrography of polished samples before and after sintering at $\left(800{ }^{\circ} \mathrm{C}\right)$. 
Subsequently, the average maximum stress resistance was determined (Figure 9).

We could observe that stress resistance increases with sintering temperature; however, above $800{ }^{\circ} \mathrm{C}$ no differences appeared. This higher stress resistance could be explained by a decrease of porosity as the temperature of sintering increases. An optimization of conditions of sintering was made at 600 and $800{ }^{\circ} \mathrm{C}$ with $650 \mathrm{mg}$ and $800 \mathrm{mg}$ pellets (Table 7).

According to these results, a temperature of $800{ }^{\circ} \mathrm{C}$ was necessary to obtain a good resistance structure. The presence of oxygen or a $\mathrm{H}_{2} / \mathrm{N}_{2}$ atmosphere during the sintering have no influence on the mechanical properties. It only influences the chemical composition of the pellet: in the presence of oxygen, a high amount of chromium oxide appears during the heat treatment.

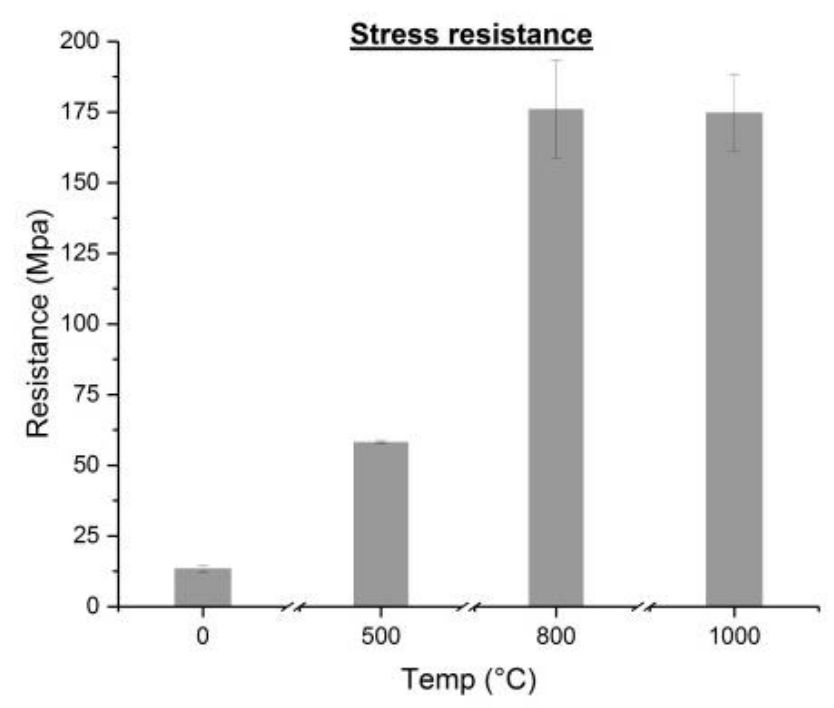

Figure 9. Comparison of maximum stress of various sintered target.

Table 7. Mechanical resistance for different masses and thicknesses of the pellets.

\begin{tabular}{|c|c|c|c|c|c|}
\hline $\begin{array}{l}\text { Mass } \\
(\mathrm{mg})\end{array}$ & $\begin{array}{c}\text { Time Compaction } \\
\text { (min) }\end{array}$ & $\begin{array}{l}\text { Sintering } \\
\text { Conditions }\end{array}$ & $\mathrm{T}\left({ }^{\circ} \mathrm{C}\right)$ & $\begin{array}{c}\text { Resistance } \\
\text { Rupture (MPa) }\end{array}$ & $\begin{array}{c}\text { Standard } \\
\text { Deviation (MPa) }\end{array}$ \\
\hline \multirow{6}{*}{650} & \multirow{6}{*}{30} & \multirow{2}{*}{ V. } & 600 & 13 & 1 \\
\hline & & & 800 & 16 & 1 \\
\hline & & \multirow{2}{*}{ N.C.A. } & 600 & 105 & 13 \\
\hline & & & 800 & 221 & 29 \\
\hline & & \multirow{2}{*}{ C.A. } & 600 & 123 & 14 \\
\hline & & & 800 & 204 & 29 \\
\hline \multirow{5}{*}{800} & 5 & C.A. & 800 & 211 & 28 \\
\hline & \multirow{4}{*}{30} & \multirow{2}{*}{ N.C.A. } & 600 & 100 & 7 \\
\hline & & & 800 & 221 & 15 \\
\hline & & \multirow{2}{*}{ C.A. } & 600 & 103 & 13 \\
\hline & & & 800 & 205 & 13 \\
\hline 650 & 30 & No sintering & / & 12 & 2 \\
\hline
\end{tabular}

V.: vacuum/C. A.: Controlled Atmosphere/C. A.N.: Not Controlled Atmosphere. 


\subsubsection{Dissolution of Target}

Tests of dissolution were then made on various pellets (variation of temperature of sintering) with $12 \mathrm{M} \mathrm{HCl}$ and heating at $200{ }^{\circ} \mathrm{C}$ on a block. These results were obtained with a pellet of $800 \mathrm{mg} 5 \mathrm{~min}$ of compaction at 8.3 tons.

Dissolution tests have been shown to have difficulties solving the target sintered up to $1000{ }^{\circ} \mathrm{C}$, but it was not necessary to complete the dissolution of pellet to extract all the ${ }^{52} \mathrm{Mn}$ [41]. However, the results reported in Table 8 would be very useful for optimizing target dissolution.

Table 8. Dissolution of target.

\begin{tabular}{|c|c|c|c|c|c|c|c|c|c|}
\hline Sintering $\mathrm{T}\left({ }^{\circ} \mathrm{C}\right)$ & 1300 & 1200 & 1000 & 800 & 650 & 600 & 600 & 550 & 500 \\
\hline Volume $12 \mathrm{M} \mathrm{HCl}(\mathrm{mL})$ & $5+5$ & $5+5$ & 10 & 10 & 10 & 10 & 20 & 10 & 10 \\
\hline $\mathrm{T}\left({ }^{\circ} \mathrm{C}\right)$ heating & 100 & 200 & 200 & 200 & 200 & 200 & 200 & 200 & 200 \\
\hline Dissolution & P. & P. & P. & P. & P. & P. & C. $(20 \mathrm{~min})$ & C. $(10 \mathrm{~min})$ & C. $(10 \mathrm{~min})$ \\
\hline$\%$ Weigh dissolved in $30 \mathrm{~min}$ & 65 & 75 & 76 & 80 & 80 & 80 & 100 & 100 & 100 \\
\hline
\end{tabular}

Although sintering at $600{ }^{\circ} \mathrm{C}$ could be suitable for the dissolution of the pellet, the breaking strength remains an essential criterion in the choice of the preparation. The sintering at $800{ }^{\circ} \mathrm{C}$ was selected for the design of this target. For the development of the separation method, this target was used (however, the thickness was still substantial at $900 \mu \mathrm{m}$ for a weight of $650 \mathrm{mg}$ ).

The dissolution of the $\mathrm{Cr}$ pellet by hydrochloric acid solution starts at the grain boundaries and increases the porosity. Scanning Electron Microscope (SEM) observations confirm that grain boundaries are attacked and material becomes more porous after the dissolution step (Figure 10).
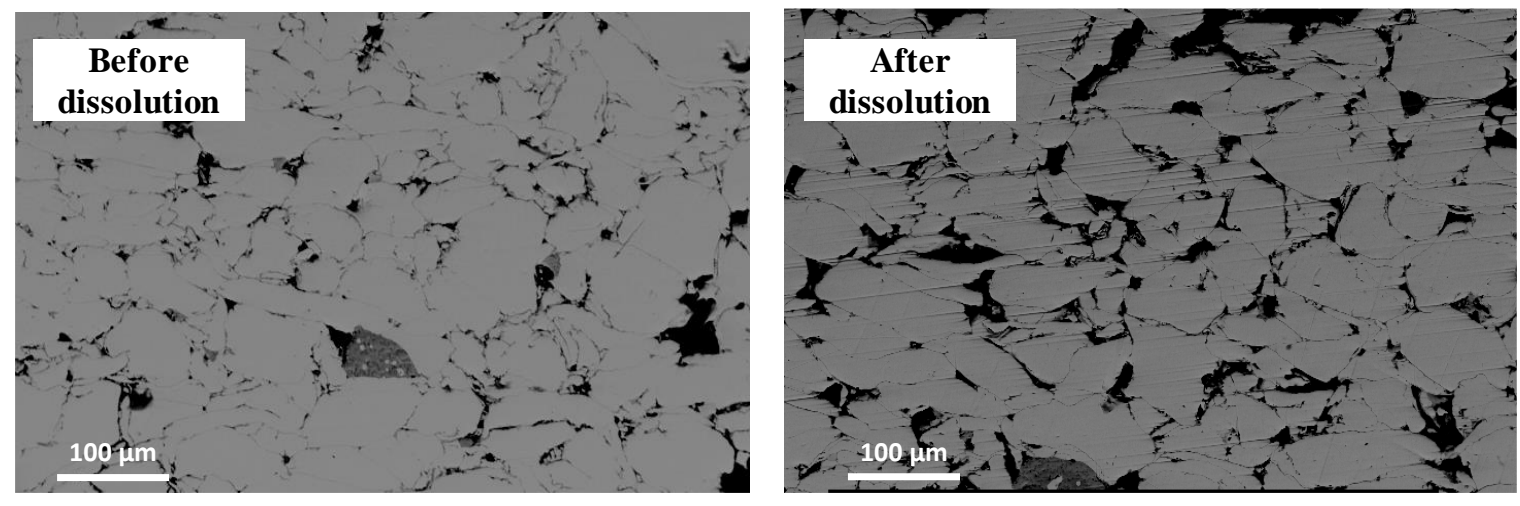

Figure 10. Scanning electron microscope (SEM) micrograph (mode BSE (back-scatter electron). of sintered pellet at $800^{\circ} \mathrm{C}$, before and after dissolution.

For temperature higher than $600{ }^{\circ} \mathrm{C}$, the densification is very high. The residual porosity is too low, the reactive surface is, therefore, too small and the acid cannot penetrate the core of the material.

Chromium is a compound that oxidizes very easily: a small amount of chromium oxide crystallizes during the sintering step or during dissolution when in contact with the acid. Chromium oxide is a stable compound that is impossible to dissolve. During dissolution, the acid solution is charged with chromium ions. At $600{ }^{\circ} \mathrm{C}$, if $10 \mathrm{~mL}$ of hydrochloric acid is set from the beginning, and the pellet does not dissolve. In contrast, an initial addition of $20 \mathrm{~mL}$ allows complete dissolution.

During sintering, the pellet is in the presence of carbon to avoid oxidation. It is possible that chromium carbide is formed and can then limit the dissolution (Figure 11) [44]. 


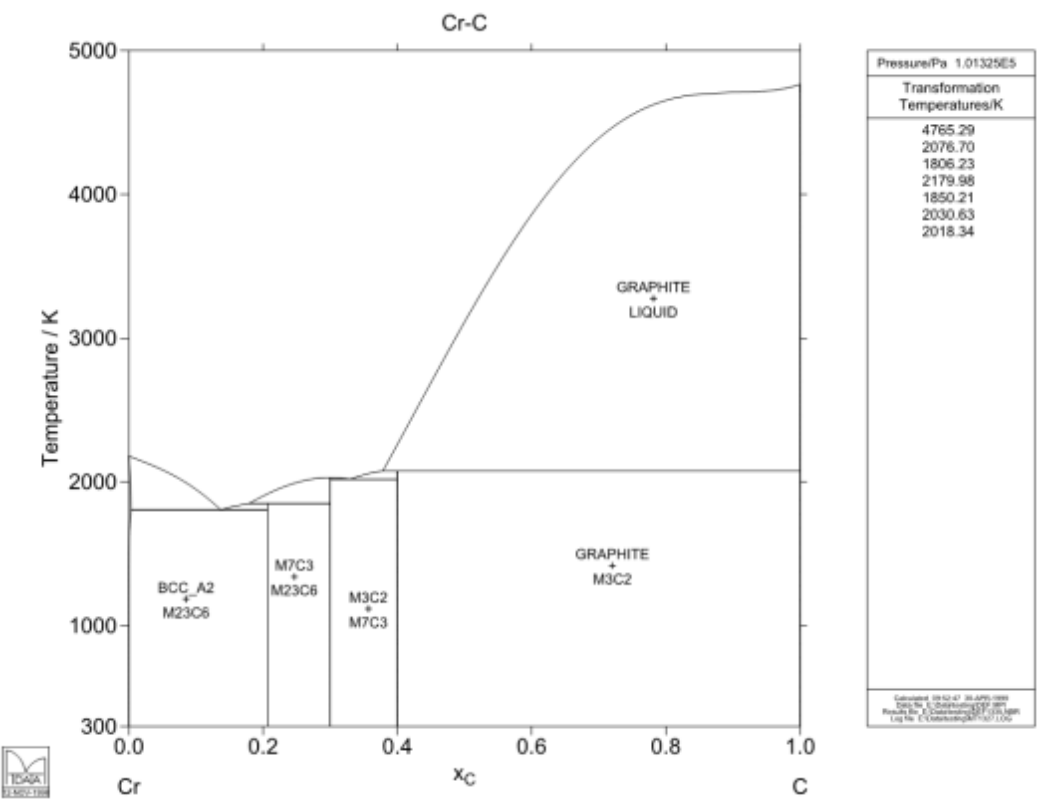

Figure 11. Cr-C phase diagram.

Nevertheless, it should be noted that the higher the density, the more difficult it is to attack with the acid during dissolution because the grains are very close. Indeed, a pellet sintered at 650 or $800{ }^{\circ} \mathrm{C}$ does not dissolve completely while a sintering at $600{ }^{\circ} \mathrm{C}$ dissolves completely.

\subsubsection{Porosity of Target}

To validate these explications, more investigations were undertaken. First, average density of the Cr pellet was determined at different conditions of sintering (by weighing pellets and measurement of thickness and diameter) (Table 9):

Table 9. Evolution of pellet density relative to sintering temperature.

\begin{tabular}{cccccc}
\hline Temperature $\left({ }^{\circ} \mathrm{C}\right)$ & $\mathbf{5 0 0}$ & $\mathbf{5 5 0}$ & $\mathbf{6 0 0}$ & $\mathbf{6 5 0}$ & $\mathbf{8 0 0}$ \\
\hline Density $(\%)$ & 76 & 80 & 75 & 77 & 82 \\
\hline (\% of theoretical density of Cr for the same volume).
\end{tabular}

As the sintering temperature increases, the density increases. Before sintering, the density of the $800 \mathrm{mg}$ pellet was $73 \%$. After sintering, the density increased. A heat treatment was used to densify the material (Figure 12). It is clear that the porosity decreased. Grains were close together or even welded.
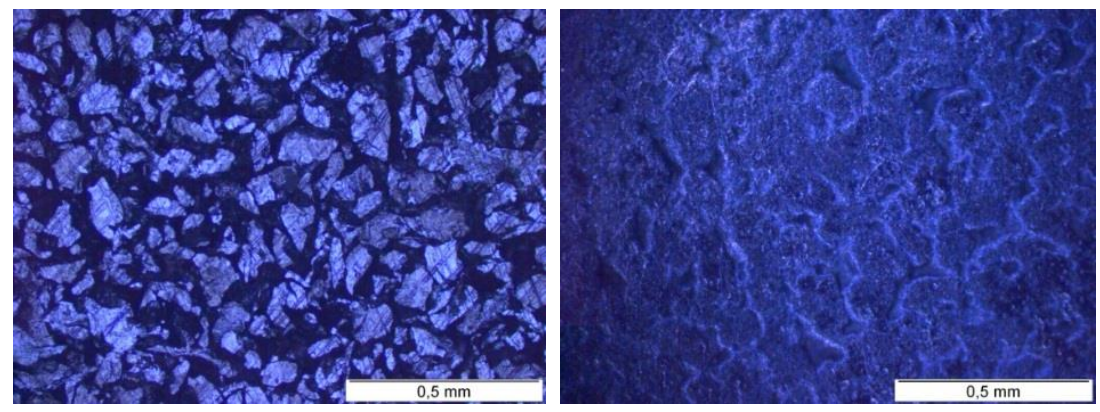

Figure 12. Micrograph of non-sintered pellet at left and sintered pellet at $1300{ }^{\circ} \mathrm{C}$ at right. 
The porosity of the pellets was then defined: this was opened and closed porosity. The closed porosity corresponds to a pore which is isolated from the others and which does not communicate with the outside. On the contrary, we observed opened porosity when the pores communicated with the outside. The results obtained are summarized in the following Figure 13.

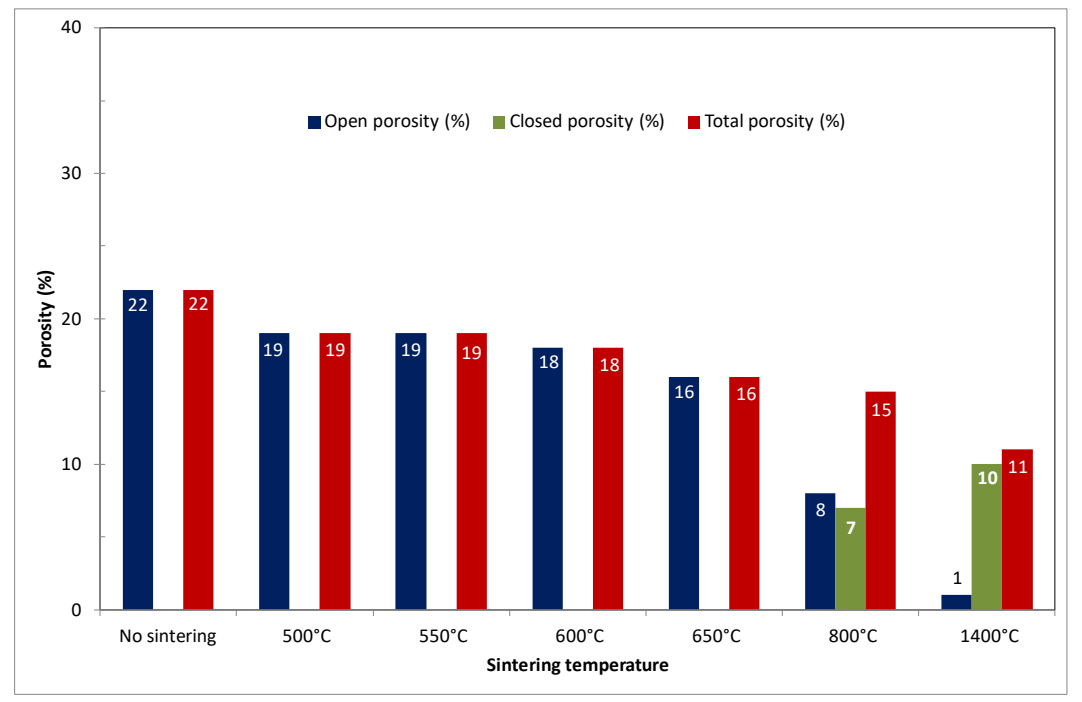

Figure 13. Evolution of the porosity of the Cr pellet with the sintering temperature.

These results show that the non-sintered chromium pellets is very porous. The higher the sintering temperature, the lower the porosity obtained. Therefore, when the porosity was very low, the attack of the acid for dissolution was difficult because the acid could not penetrate the core of the pellet and attack grain boundaries and grains. This may also explain why a pellet sintered at $600{ }^{\circ} \mathrm{C}$ dissolved easily while sintering at $800^{\circ} \mathrm{C}$ did not completely dissolve.

To understand the ability to dissolve as a function of the sintering temperature, the evolution of the microstructure as a function of temperature was followed. For this, observations in optical microscopy and SEM were performed. Some micrographs are presented in the following Figures 14 and 15.

The heat treatment of the $\mathrm{Cr}$ pellet in $\mathrm{N}_{2} / \mathrm{H}_{2}$ atmosphere and in a crucible containing graphite powder induced the formation of small areas of chromium oxide (because of residual oxygen adsorbed in the porosity) and the formation of a chromium carbide, when the temperature was higher, for example $1400{ }^{\circ} \mathrm{C}$ : chromium carbide was formed from the chromium of the pellet and the carbon powder. During the dissolution step, these two compounds will not facilitate the attack of the pellet with hydrochloric acid.

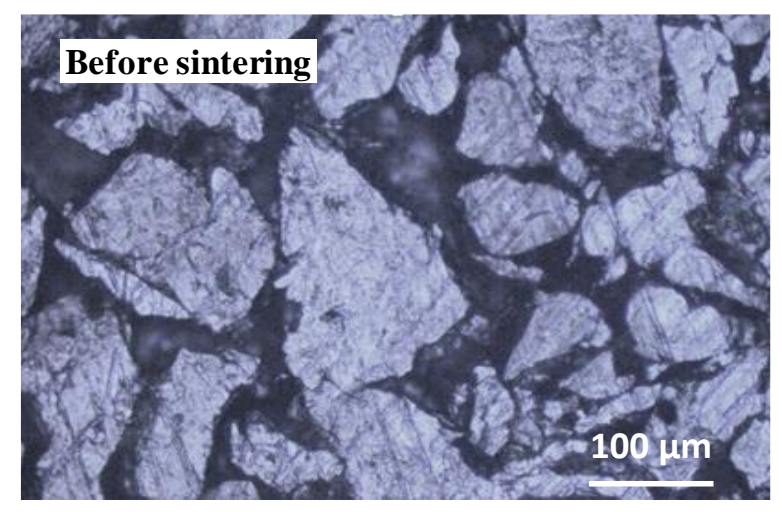

Figure 14. Micrography of a $800 \mathrm{mg} \mathrm{Cr}$ pellet before sintering (optical microscope). 

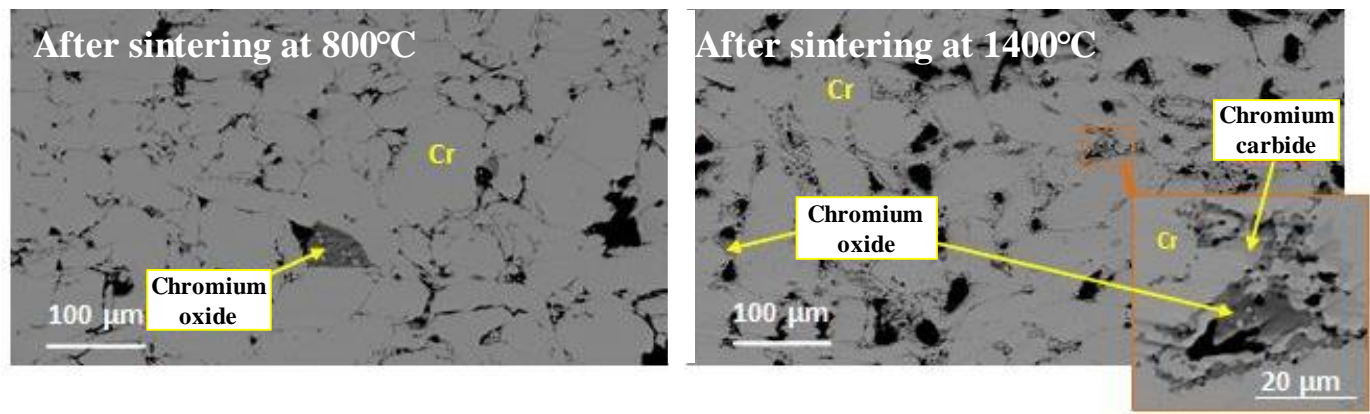

Figure 15. Micrography of a $800 \mathrm{mg} \mathrm{Cr}$ pellet after sintering and polished (SEM).

X-ray diffraction (XRD) analysis was performed on a pellet sintered at $800{ }^{\circ} \mathrm{C}$ (Figure 16). These results highlights the presence of chromium metal in the majority phase and the presence of traces of eskolaite $\mathrm{Cr}_{2} \mathrm{O}_{3}$. This result is consistent with observations and analysis made by SEM.
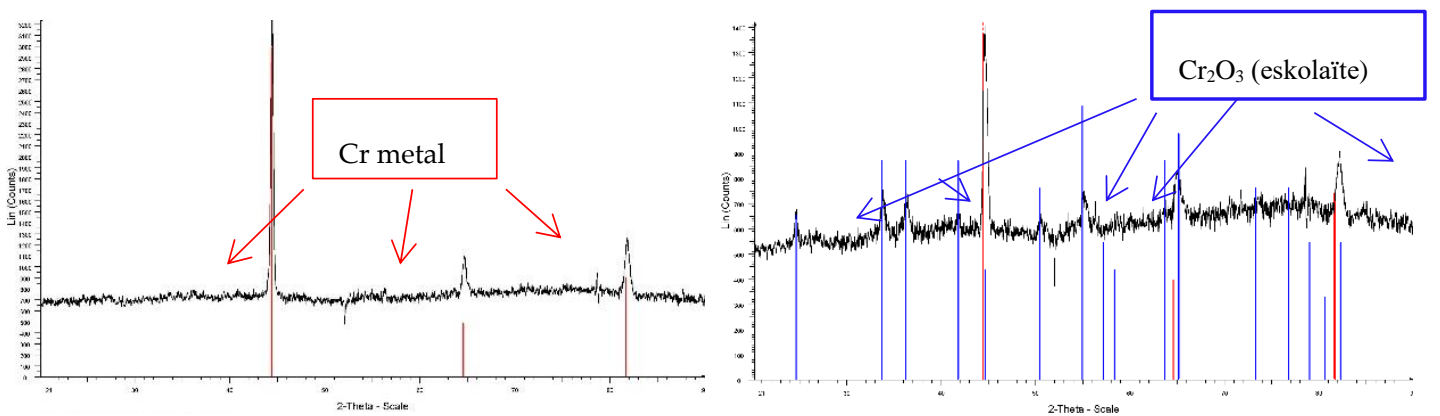

Figure 16. XRD diffractograms of pellet before and after sintering at $800{ }^{\circ} \mathrm{C}$.

\subsection{6. $\mathrm{D}_{\mathrm{w}}$ in Separation of $\mathrm{Cr} / \mathrm{Mn}$}

Figure 17 presents these results. With an eluent without ethanol, no separation between $\mathrm{Cr}$ and Mn was observed. An ethanolic eluent (93 to 98\%) modified impressively this separation. Cr was not retained on $\mathrm{AG} 1 \times 8^{\circledR}$ resin whereas $\mathrm{Mn}$ was and $\mathrm{D}_{\mathrm{w}}$ was bigger as $\mathrm{HCl}$ concentration of the eluent solution increased.

These results were in agreement with literature [40] but, in our case, less activity was undertaken for nuclear safety considerations and less contact time $(1 \mathrm{~h})$. Agreements of $\mathrm{D}_{\mathrm{w}}$ with published results have led us to make a first test of the semi-automation of the $\mathrm{Cr} / \mathrm{Mn}$ separation.

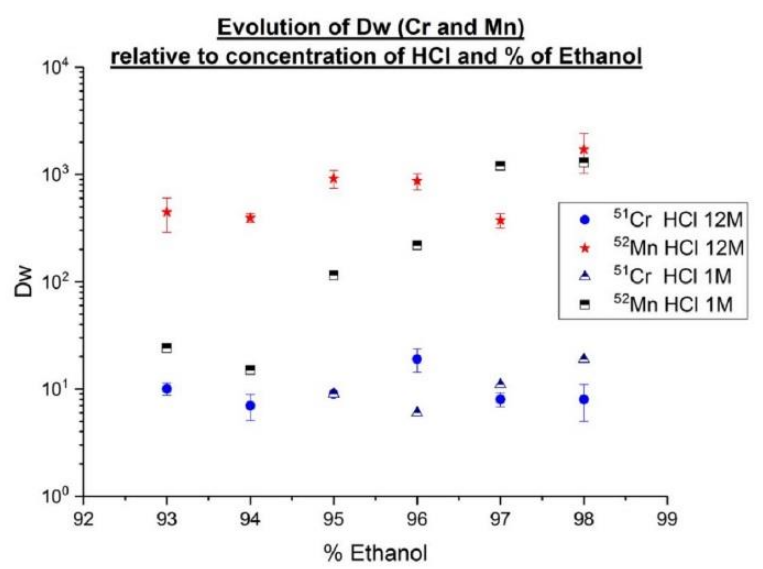

Figure 17. $\mathrm{D}_{\mathrm{w}}$ of $\mathrm{Mn}$ and $\mathrm{Cr}$. 


\subsubsection{Semi-Automated Separation of $\mathrm{Cr} / \mathrm{Mn}$}

It is necessary to modify the remote-control sketch of ${ }^{165} \mathrm{Er}$ for use in the extraction of ${ }^{52} \mathrm{Mn}$, and this requires three columns at least to obtain a suitable separation (Figure 18).

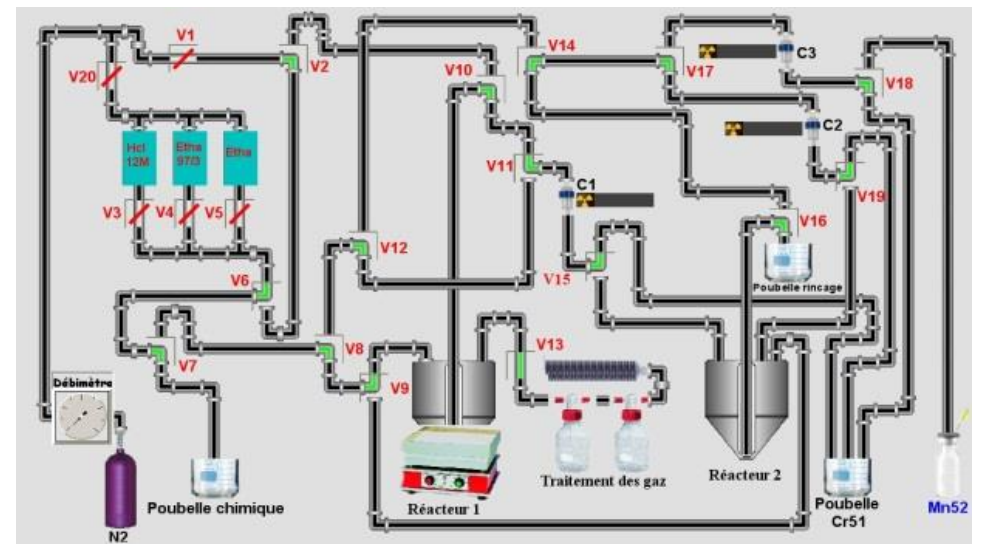

Figure 18. Remote control of Mn/Cr separation.

Results for the first test, with weak activity, on a semi-automation of separation $\mathrm{Mn} / \mathrm{Cr}$ are listed in Table 10.

Table 10. Extraction yield in semi-automation separation of $\mathrm{Mn} / \mathrm{Cr}$.

\begin{tabular}{ccccc}
\hline & & Volume & \multicolumn{2}{c}{ Y (\%) } \\
\hline & & $\mathbf{( m L )}$ & ${ }^{51} \mathbf{C r}$ & ${ }^{52} \mathbf{M n}$ \\
\hline \multirow{3}{*}{ Column 1 } & Sample & 8.2 & 91.2 & 0.0 \\
& Eluent F1 & 3.7 & 2.8 & 0.0 \\
& Eluent F2 & 3.4 & 0.6 & 0.0 \\
& Eluent F3 & 3.3 & 0.3 & 0.0 \\
& HCl 12 M & 1.3 & 0.0 & 76.5 \\
\hline \multirow{3}{*}{ Column 2 } & Sample & 29.6 & 0.0 & 0.0 \\
& Eluent F1 & 3.4 & 0.0 & 0.0 \\
& HCl 12 M & 1.0 & 0.0 & 81.7 \\
\hline \multirow{2}{*}{ Column 3 } & Sample & 21.8 & 0.0 & 0.0 \\
& Eluent F1 & 3.5 & 0.0 & 0.0 \\
\hline Global Yield (\%) & HCl 12 M & 1.5 & 0.0 & 83.8 \\
\hline
\end{tabular}

Chromium was recovered in the first batch: it was not so much adsorbed on column 1 as was ${ }^{52} \mathrm{Mn}$. Global recovery of ${ }^{52} \mathrm{Mn}$ was less than $50 \%$ ( ${ }^{*}$ calculated on the final batch of ${ }^{52} \mathrm{Mn}$ : initial activity / final activity in batch).

\subsubsection{Reduction of Pellet Thickness}

To optimize the target design of a Cr pellet, a reduction of the target thickness and, by this way, a limitation of non-irradiated $\mathrm{Cr}$ mass, polishing is a useful solution.

This operation reduced the amount of chromium handled during the extraction process. Thickness was reduced by one third (from $900 \mu \mathrm{m}$ to $350 \mu \mathrm{m}$ ) and the oxide layer on surface of target was removed.

\section{Discussion}

The cyclotron of Orléans is a multipurpose research accelerator (proton, deuteron and alpha at various energy from 10 to $45 \mathrm{MeV}$ ). With these specifications, more radionuclides can be accessed than in a commercial cyclotron. In this work, we demonstrate its capabilities for development of exotic 
radionuclides like ${ }^{165} \mathrm{Er}$ and ${ }^{52} \mathrm{Mn}$. It is a wonderful tool for a radiochemist to product radionuclides aimed at imaging as well as analytical applications too (radiotracer method). But, with energy of $30 \mathrm{MeV}$, most of SPECT isotopes are produced by reactions ( $p, 2 n)$ or $(p, 3 n)$ [45]. Even when one has the choice between $(p, n)$ and $(p, 2 n)$, e.g., for ${ }^{67} \mathrm{Ga}$ one favors $(p, 2 n)$ reaction for the yield (thicker targets, less warming by $\mu \mathrm{A}$ ). For these two radionuclides produced at the cyclotron of Orléans, the first tool developments for separative radiochemistry have been made.

In the case of ${ }^{165} \mathrm{Er}$, separation $\mathrm{Er} / \mathrm{Ho}$ needed to be better understood and a real improvement could also be made to facilitate semi-automation.

For a limited volume of isolated ${ }^{165} \mathrm{Er}$ fraction with elution of $1 \mathrm{M} \mathrm{HNO}_{3}$, a NaI detector with two windows at $53 \mathrm{keV}$ and $80 \mathrm{keV}$ could be a solution. On the other hand, more detailed developments on geometric parameters on the elution curve are necessary because LN2 resin has a limited capacity for adsorption.

Semi-automation proved necessary with increased activity of ${ }^{165} \mathrm{Er}$ by the deuteron method. A more sensitive evaluation of the quality of a ${ }^{165} \mathrm{Er}$ batch and its ratio ${ }^{166+165(n a t)} \mathrm{Ho} / \mathrm{Er}$ must be performed more carefully regarding the quality of the irradiated target and the by-products generated. Additional analysis by ICP-MS is necessary to complete these validations. At least, this protocol of separation $\mathrm{Ho} /$ Er can already be adapted as it answers issues of radiolanthanides extraction where the separation of micro- from macrocomponents is crucial.

This work made it possible to obtain a $\mathrm{Cr}$ target for the production of ${ }^{52} \mathrm{Mn}$ for irradiation and method development tests: $650 \mathrm{mg}$ of powder sintered at $800^{\circ} \mathrm{C}$ for $1 \mathrm{~h}$ (thickness $900 \mu \mathrm{m}$ ).

In a detailed analysis of results of compaction, a test at 4 tons on $650 \mathrm{mg}$ pellet gave a bad visual aspect and greater thickness of $1000 \mu \mathrm{m}$ than those made at 8.3 tons $(900 \mu \mathrm{m})$ : density must be lower which is not interesting for an irradiation (mechanical firmness). A surprising result is compaction of $60 \mathrm{~min}$ at 8.3 tons on $650 \mathrm{mg}$ pellet that gave a bad visual aspect. This can be explained by the fact that its time in pressed state can generated micro crack. Then, when the pellet is relieved of stress, the pellet cracked.

Regarding the conditions of sintering, at vacuum no difference with a pellet not-sintered has seen. This can be perhaps explain by system of sintering: temperature has defined by emissivity of molybdenum where pellets are put. A second explanation might be that more vacuum is, less tension surface on grain is. With a reduction of tension surface, grain boundaries are more difficult to form.

Between $600{ }^{\circ} \mathrm{C}$ and $800^{\circ} \mathrm{C}$, resistance rupture is twice as big. There is no relation between weight and resistance rupture. The optimum temperature of state transition is between $600{ }^{\circ} \mathrm{C}$ and $800{ }^{\circ} \mathrm{C}$. Resistance rupture is less altered by the weight of the pellet than the temperature.

Breaking measurements must be carried out on the polished targets of 300-400 $\mu \mathrm{m}$ thickness as well as dissolution tests.

\section{Conclusions}

The production of ${ }^{165} \mathrm{Er}$ from a natural Ho target was obtained via deuteron irradiation. This form of irradiation generated more activity than the proton method, with much activity of ${ }^{166} \mathrm{Ho}$ (a radiotracer for Ho). LN2 resin (from Triskem) was used to separate Er and Ho with nitric acid solution. Selectivity between two radiolanthanides was weak ( $\mathrm{SF} \mathrm{Er} / \mathrm{Ho}=2.75$ at $0.4 \mathrm{M} \mathrm{HNO}_{3}$ ) but an isolated fraction with $72.3 \pm 5.1 \%(n=4)$ of initial ${ }^{165} \mathrm{Er}$ activity can be achieved by an appropriate gradient of elution with $0.4 \mathrm{M}(120 \mathrm{~mL})$ and $1 \mathrm{M} \mathrm{HNO}_{3}(40 \mathrm{~mL})$. In this fraction, the mass of holmium was reduced by a factor $1294 \pm 1183(n=3)$. Regarding ${ }^{52} \mathrm{Mn}$ production, a design of the target has been established: a Cr pellet of $800 \mathrm{mg}$ compressed at 8.3 tons (300 bars) and sintered at $800{ }^{\circ} \mathrm{C}$. Elution on $\mathrm{AG} 1 \times 8^{\circledR}$ resin with a mixture of ethanol/ $\mathrm{HCl}(12 \mathrm{M})(97 / 3(v / v)$ gave good results for the separation of ${ }^{51} \mathrm{Cr}$ from ${ }^{52} \mathrm{Mn}$. A test of semi-automation separation using three columns was made with a diluted solution of ${ }^{51} \mathrm{Cr}$ and ${ }^{52} \mathrm{Mn}$. A global extraction of $47 \%$ on ${ }^{52} \mathrm{Mn}$ was obtained.

For these two radiometals, ${ }^{165} \mathrm{Er}$ and ${ }^{52} \mathrm{Mn}$, results were encouraging for the following experiments: some improvements are underway concerning the irradiation and the targeting. For the 
separation, a methodology about more detailed developments on geometric parameters on the elution curve must have been set. The first results of the Er/Ho and $\mathrm{Mn} / \mathrm{Cr}$ separation on a semi-automated system demonstrated the versatility of the homemade system. However, these tests have been shown to require more reliability and reproducibility in the separation step with a better follow-up on line using adapted sensors.

Author Contributions: E.D. and F.D. worked on production of radionuclides for the ratiotracer method (definition of beam) and developed the simple tool to predict a nuclear reaction for a radiochemist; J.V. and M.G. worked on the design of the Cr-target and performed experiences on chemical and physical specifications of Cr-pellet; M-L.B. contributed to the design of the Cr-target through knowledge in materials and methods of analysis; G.A. (spectrometry $\gamma$ ), E.S. $\left({ }^{52} \mathrm{Mn}\right)$ and C.R. $\left({ }^{165} \mathrm{Er}\right)$ performed the experiments for determination of Dw and tests of resin; L.F. designed the automation of the process and analyzed the data by spectrometry $\gamma$; A.B. contributed reagents/materials/analysis tools and the definition of Er/Ho separation by using resin LN2 (Triskem); I.D.S. conceived the radiotracer methods, defined conditions of experiments and participated in all steps of these various works, and wrote the paper; I.D.S. would like to thank G. Junot $\left({ }^{64} \mathrm{Cu}\right), \mathrm{K}$. Blanchard $\left({ }^{64} \mathrm{Cu}\right)$, D. Barré $\left({ }^{11} \mathrm{C}\right)$, A. Fournier $\left({ }^{64} \mathrm{Cu}\right), \mathrm{L}$. Colas $\left({ }^{11} \mathrm{C}\right), \mathrm{L}$. Léost $\left({ }^{64} \mathrm{Cu}\right)$, A. Sabourin $\left({ }^{11} \mathrm{C}\right), \mathrm{C}$. Dupressoir $\left({ }^{64} \mathrm{Cu}\right)$ and N. Mialon $\left({ }^{11} \mathrm{C}\right)$ for their work contributing to the setup of radiochemistry at the cyclotron of Orléans and, indirectly, to this article.

Funding: This research had financial support of Triskem Society and AAP_Défi 2017 "Instrumentation aux limites "project "CiSCoTe": Cible Solide irradiée Contrôlée en Température". It funded too by the French National Research Agency (grant ANR-13-JS07-0007).

Conflicts of Interest: The authors declare no conflict of interest.

\section{References}

1. Zeglis, B.M.; Houghton, J.L.; Evans, M.J.; Viola-Villegas, N.; Lewis, J.S. Underscoring the Influence of Inorganic Chemistry on nuclear Imaging with Radiometals. Inorg. Chem. 2014, 53, 1880-1899. [CrossRef] [PubMed]

2. Brasse, D.; Nonat, A. Radiometals: Towards a new success story in nuclear imaging? Dalton Trans. 2015, 44, 4845-4858. [CrossRef] [PubMed]

3. Müller, C.; Van Der Meulen, N.P.; Benesová, M.; Schibli, R. Therapeutic Radiometals Beyond ${ }^{177}$ Lu and ${ }^{90}$ Y: Production and Application of Promising $\alpha$-particle, $\beta^{-}$-Particle, and Auger Electron Emitters. J. Nucl. Med. 2017, 58, 91S-96S. [CrossRef] [PubMed]

4. Amoroso, A.J.; Fallis, I.A.; Pope, S.J.A. Chelating agents for radiolanthanides: Applications to imaging and therapy. Coordin. Chem. Rev. 2017, 340, 198-219. [CrossRef]

5. Guérard, F.; Rajerison, H.; Faivre-Chauvet, A.; Barbet, J.; Meyer, G.J.; Haddad, F.; Da Silva, I.; Gestin, J.-F. Radiolabeling proteins with stabilised hypervalent astatine-211: Feasability study and evaluation of the in vitro stability. Eur. J. Nucl. Med. Mol. Imaging 2010, 37, S361.

6. Rajerison, H.; Guérard, F.; Mougin-Degraef, M.; Bourgeois, M.; Da Silva, I.; Chérel, M.; Barbet, J.; Faivre-Chauvet, A.; Gestin, J.-F. Radioiodinated and astatinated NHC rhodium complexes: Synthesis. Nucl. Med. Biol. 2014, 41, e23-e29. [CrossRef] [PubMed]

7. Sergentu, D.C.; Teze, D.; Sabatié-Gogova, A.; Alliot, C.; Guo, N.; Bassal, F.; Da Silva, I.; Deniaud, D.; Maurice, R.; Champion, J.; et al. Advances on the Determination of the Astatine Pourbaix Diagram: Predomination of AtO $(\mathrm{OH}) 2-$ over At- in Basic Conditions. Chem. Eur. 2016, 22, 2964-2971. [CrossRef] [PubMed]

8. Alliot, C.; Chérel, M.; Barbet, J.; Sauvage, T.; Montavon, G. Extraction of astatine-211 in diisopropylether (DIPE). Radiochim. Acta 2009, 97, 161-165. [CrossRef]

9. Meijs, W.E.; Herscheid, J.D.M.; Haisma, H.J.; Wijbrandts, R.; Van Langevelde, F.; Van Leuffen, P.J.P.; Mooy, R.; Pinedo, H.M. Production of Highly Pure no-carrier added ${ }^{89} \mathrm{Zr}$ for the labelling of antibodies with a positron emitter. Appl. Radiat. Isot. 1994, 45, 1143-1147. [CrossRef]

10. National Nuclear Data Center. Available online: https://www.nndc.bnl.gov/chart/decaysearchdirect.jsp? nuc $=165 E R \& u n c=$ nds (accessed on 23 February 2018).

11. Beyer, G.J.; Zeisler, S.K.; Becker, D.W. The Auger-electron emitter ${ }^{165}$ Er: Excitation function of the ${ }^{165} \mathrm{Ho}(\mathrm{p}, \mathrm{n}){ }^{165} \mathrm{Er}$ process. Radiochim. Acta 2004, 92, 219-222. [CrossRef] 
12. Malikidogo, P.K.; Da Silva, I.; Morfin, J.-F.; Lacerda, S.; Barentin, L.; Sauvage, T.; Sobilo, J.; Lerondel, S.; Toth, E.; Bonnet, C. A cocktail of $165 \mathrm{Er}^{3+}$ and $\mathrm{Gd}^{3+}$ complexes for quantitative detection of zinc by SPECT/MRI. Chem. Commun. 2018. [CrossRef] [PubMed]

13. Tárkányi, F.; Hermanne, A.; Takács, S.; Ditrói, F.; Király, B.; Kovalev, S.F.; Ignatyuk, A.V. Experimental study of the ${ }^{165} \mathrm{Ho}(\mathrm{d}, 2 \mathrm{n})$ and ${ }^{165} \mathrm{Ho}(\mathrm{d}, \mathrm{p})$ nuclear reactions up to $20 \mathrm{MeV}$ for production of the therapeutic radioisotopes ${ }^{165} \mathrm{Er}$ and ${ }^{166 \mathrm{~g}} \mathrm{Ho}$. Nucl. Instrum. Meth. B 2008, 266, 3529-3534. [CrossRef]

14. Tárkányi, F.; Hermanne, A.; Király, B.; Takács, S.; Ditrói, F.; Baba, M.; Ohtsuki, T.; Kovalev, S.F.; Ignatyuk, A.V. Study of activation cross-sections of deuteron induced reactions on erbium: Production of radioisotopes for practical applications. Nucl. Instrum. Meth. B 2007, 259, 829-835. [CrossRef]

15. Graves, S. Production and Applications of Long-Lived Positron Emitting Radionuclides. Ph.D. Thesis, University of Wisconsin-Madison, Madison, WI, USA, 6 January 2017.

16. Le Loirec, C. Track structure simulation for positron emitters of physical interest. Part II: The case of the radiometals. Nucl. Instrum. Meth. A 2007, 582, 654-664. [CrossRef]

17. Disselhorst, J.A.; Brom, M.; Laverman, P. Image-Quality Assessment for Several 570 Positron Emitters Using the NEMA NU 4-2008 Standards in the Siemens Inveon Small-Animal PET Scanner. J. Nucl. Med. 2010, 51, 610-617. [CrossRef] [PubMed]

18. Sastri, C.S. Production of Manganese- 52 of high isotopic purity by ${ }^{3}$ He activation of Vanadium. Int. J. Appl. Radiat. Isot. 1981, 32, 246-247. [CrossRef]

19. Daube, M.E.; Nickles, R.J. Development of myocardial perfusion tracers for positron emission tomography. Int. J. Nucl. Med. Biol. 1985, 12, 303-314. [CrossRef]

20. Tolmachev, V.; Bruskin, A.; Lunqvist, H. Neutron Deficient Nuclides for Positron Emission Tomography. IX. Preliminary Study of Production Routes of Positron Emitting Isotopes of Manganese; Institute of Theoretical and Experimental Physics: Moscow, Russia, 1994; pp. 47-94.

21. Calandroni, D.; Dupuis, A.; Grémont, B.; Hurt, B.; Kervizic, J.; Meyrand, G.; Tran, D.T. Some characteristics from Orléans and Liège cyclotrons. In Proceedings of the Seventh International Conference on Cyclotrons and their Applications, Zurich, Switzerland, 19-22 August 1975; pp. 88-91.

22. Dupuis, A.; Kervizic, J.; Launé, B.; Meyrand, G.; Tran, D.T.; Tronc, D.; Goin, G. Cyclotron center region study and beam diagnostic at Orléans cyclotron. In Proceedings of the Seventh International Conference on Cyclotrons and their Applications, Zurich, Switzerland, 19-22 August 1975; pp. 275-278.

23. Goin, G. Status report on the CNRS Orleans' cyclotron. In Proceedings of the 9th International Conference on Cyclotrons and their Applications, Caen, France, 7-10 September 1981; pp. 133-135.

24. Goin, G.; Vernois, J.; Cimetiere, C.; Leger, J. Iodine 123 production by irradiation at the CNRS cyclotron in Orléans. In Proceedings of the 9th International Conference on Cyclotrons and theirs Applications, Caen, France, 7-10 September 1981; pp. 697-698.

25. Breteau, N.; Sabattier, R.; Gueulette, J.; Bajard, J.C. The Orléans neutrontherapy facility. In Proceedings of the 9th International Conference on Cyclotrons and theirs Applications, Caen, France, 7-10 September 1981; pp. 703-705.

26. Tárkányi, F.; Takács, S.; Hermanne, A.; Ditrói, F.; Király, B.; Baba, M.; Ohtsuki, T.; Kovalev, S.F.; Ignatyuk, A.V. Investigation of production of the therapeutic radioisotope ${ }^{165} \mathrm{Er}$ by proton induced reactions on erbium in comparison with other production routes. Appl. Radiat. Isot. 2009, 67, 243-247. [CrossRef] [PubMed]

27. Zandi, N.; Sadeghi, M.; Afarideh, H. Evaluation of the cyclotron production of ${ }^{165} \mathrm{Er}$ by different reactions. J. Radioanal. Nucl. Chem. 2013, 295, 923-928. [CrossRef]

28. Korkisch, J. Rare Earth Elements in Handbook of Ion Exchange Resins: Their Application to Inorganic Analytical Chemistry; CRC Press: Boca Raton, FL, USA, 1989; ISBN 0-8493-3191-9.

29. Nifant'ev, I.E.; Minyaev, M.E.; Tavtorkin, A.N.; Vinogradov, A.A.; Ivchenko, P.V. Branched alkylphosphinic and disubstituted phosphinic and phosphonic acids: Effective synthesis based on $\alpha$-olefin dimers and applications in lanthanide extraction and separation. RSC Adv. 2017, 7, 24122-24128. [CrossRef]

30. Xie, F.; Zhang, T.A.; Dreisinger, D.; Doyle, F. A critical review on solvent extraction of rare earths from aqueous solutions. Miner. Eng. 2014, 56, 10-28. [CrossRef]

31. Reddy, M.L.P.; Rao, P.; Damodaran, A.D. Liquid-liquid extraction processes for the separation and purification of rare earths. Miner. Process. Extract. Metall. Rev. 1995, 12, 91-113. [CrossRef]

32. Horwit, E.P.; Bloomquist, C.A.A. Chemical separation for heavy elements searches in irradiated uranium targets. J. Inorg. Nucl. Chem. 1975, 37, 425-434. [CrossRef] 
33. Kazakov, A.G.; Aliev, R.A.; Bodrov, A.Y.; Priselbova, A.B.; Kamlykov, S.N. Separation of radioisotopes of terbium from a europium target irradiated by $27 \mathrm{MeV} \alpha$-particles. Radiochim. Acta 2018, 106, 135-140. [CrossRef]

34. Hidaka, H.; Yoneda, S. Sm and Gd isotopic shifts of Apollo 16 and 17 drill stem samples and their implications for neolith history. Geochim. Cosmochim. Acta 2007, 71, 1074-1086. [CrossRef]

35. Monroy-Guzman, F.; Jaime Salinas, E. Separatin of Micro-Macrocomponent Systems: $149 \mathrm{Pm}-\mathrm{Nd}, 161 \mathrm{~Tb}-\mathrm{gd}$, 166Ho-Dy, and 177Lu-Yb by Extraction Chromatography. J. Mex. Chem. Soc. 2015, 59, 143-150.

36. Horwitz, E.P.; McAlister, D.R.; Dietz, M.L. Extraction chromatography versus solvent extraction: How similar are they? Sep. Sci. Technol. 2006, 41, 2163-2182. [CrossRef]

37. Shu, Q.; Khayambashi, A.; Zou, Q.; Wang, X.; Wei, Y.; He, L.; Tang, F. Studies on adsorption and separation characteristics of americium and lanthanides using a silica-based macroporous bi(2-ethylhexyl)phosphoric acid (HDEHP) adsorbent. J. Radioanal. Nucl. Chem. 2017, 313, 29-37. [CrossRef]

38. Lake Wooten, A. Cross-sections for $(\mathrm{p}, \mathrm{x})$ reactions on natural chromium for the production of ${ }^{52,52 \mathrm{~m} M n},{ }^{54} \mathrm{Mn}$ radioisotopes. Appl. Radiat. Isot. 2015, 96, 154-161. [CrossRef] [PubMed]

39. Lahiri, S.; Nayak, D.; Korschinek, G. Separation of no-carrier-added ${ }^{52} \mathrm{Mn}$ from bulk chromium: A simulation study for Accelerator Mass Spectrometry measurement of ${ }^{53} \mathrm{Mn}$. Anal. Chem. 2006, 78, 7517-7521. [CrossRef] [PubMed]

40. Fonslet, J.; Tietze, S.; Jensen, A.I.; Graves, S.A.; Severin, G.W. Optimized procedures for manganese-52: Production, separation and radiolabelling. Appl. Radiat. Isot. 2017, 121, 38-43. [CrossRef] [PubMed]

41. Graves, S.; Hernandez, R.; Fonslet, J.; England, C.G.; Valdovinos, H.F.; Ellison, P.A.; Barnhart, T.E.; Elema, D.R.; Theuer, C.P.; Cai, W.; et al. Novel preparation methods of 52Mn for immunoPET imaging. Bioconjugate Chem. 2015, 26, 2118-2124. [CrossRef] [PubMed]

42. Westergaard, H.M. Stresses in Concrete Pavements Computed by theoretical analysis. Public Roads 1926, 7, 2-25.

43. François, D.; Pineau, A.; Zaoui, A. Comportement Mécanique des Matériaux; Hermès: Paris, France, 1995; Chapter 4; pp. 402-437.

44. National Physical Laboratory. Available online: http://resource.npl.co.uk/mtdata/phdiagrams/ccr.htm (accessed on 22 June 2018).

45. Scientific Report of Nuclear Physics European Collaboration Committee (NuPECC) 2014 Nuclear Physics for Medicine. Available online: http://www.nupecc.org/pub/npmed2014_brochure.pdf (accessed on 22 June 2018).

(c) 2018 by the authors. Licensee MDPI, Basel, Switzerland. This article is an open access article distributed under the terms and conditions of the Creative Commons Attribution (CC BY) license (http:/ / creativecommons.org/licenses/by/4.0/). 